\title{
Revealing Opportunities for 21st Century Learning: An Approach to Interpreting User Trace Log Data
}

\author{
Caitlin K. Martin, Denise Nacu, Nichole Pinkard \\ Digital Youth Network, DePaul University, USA \\ College of Computing and Digital Media, DePaul University, USA
}

\begin{abstract}
Online environments can cultivate what have been referred to as 21st century skills and capabilities, as youth contribute, pursue, share, and interact around work and ideas. Such environments also hold great potential for addressing digital divi des related to the devel opment of such skills by connecting youth in areas with fewer resources and opportunities to social and material supports for learning. However, even with increasing attention to the importance of 21st century skills, there is still relatively little known about how to measure these sorts of competencies effectively. In this paper, we offer an exploratory approach for interpreting student user trace log data to reveal opportunities for creative production, self-directed learning, and social learning online. Our approach engages social learning analytics to code actions according to relationships between users and engages in self-report and ethnographic methods to supplement initial results. We share our methods; provide rich description of the unique learning environment; present results of logged opportunities for creative production, selfdirected learning, and social learning across the sixth grade cohort; and explore these results through the lens of individual learners, including cohort self-reports of identity, interest, and perceptions, and qualitative case studies of two students.
\end{abstract}

Keywords: Social learning analytics, K-12 learning environments, middle school, creative production, self-directed learning, learning communities

\section{INTRODUCTION}

Online environments for $\mathrm{K}-12$ learning are escalating in both their design and their adoption into formal and informal education spaces (Bell et al., 2009; Allen \& Seaman, 2008). At the same time, there is increasing attention, reflected in national policy reports and standards for K-12 learning, on the development of skills and dispositions necessary for productive participation in the 21st centu ry. Exact definitions vary, but there is general agreement about the importance of interpersonal capab ilities, such as communication and collaboration, and individual capacities, such as creativity and persistence (e.g., Partnership for 21st Century Skills, 2011; Pellegrino \& Hilton, 2012). There is evidence to suggest that online environments can cultivate these sorts of skills and capabilities, as youth contribute, pursue, share, and interact around work and ideas (e.g., Jenkins, Purushotma, Weigel, Clinton, \& Robison, 2009; Ito et al., 2009). Online networked environments also hold great potential for ad dressing digital divides related to the development of such skills by connecting youth in areas with fewer resources and 
(2016). Revea ling opportunities for $21^{\text {st }}$ century learning: An approach to interpreting user trace log data. Journal of Learning Ana lytics, 3 (2), 37-87. http:// dx.doi.org/10.18608/jla.2016.32.4

opportunities to social and material supports for learning (Aspen Institute, 2014; US Department of Education, 2010).

Despite this situation that seems poised for impact, we still have much to learn about what works in $\mathrm{K}-$ 12 online learning in terms of design features, content, and pedagogy, how to provide evidence of outcomes, or even what those outcomes are (Means, Bakia, \& Murphy, 2014). What we do know is that many online instantiations used in educational settings mirror traditional learning environments and practices, where a teacher provides assignments and students submit work and are graded on completed work and time on task (McGloughlin \& Lee, 2010; Bacow, Bowen, Guthrie, Lack, \& Long, 2012). We also know that development of those abilities articulated as necessary for productive citizenship in the 21st century demand more than traditional instructional approaches (Barron, Gomez, Pinkard, \& Martin, 2014; Bell et al., 2009), and that evidence of these types of nuanced capacities are difficult to measure.

As such, there is a growing recognition that we need a variety of methods to conceptualize and measure success and learning in online platforms, and that it might look different for different communiti es and contexts, even those using the same technical system (e.g., Breslow et al., 2013; Means, Bakia, \& Murphy, 2014). In this paper, we share one approach for using learning analytics to look at evid ence of 21 st century learning activities exhibited by young learners as they engage in $\mathrm{K}-12$ onl ine environments. Specific research questions driving our work are these:

How can we identify evidence of potential opportunities for 21st century learning activities in log data of user traces?

How can we better understand 21st century online learning activity patterns in different communities of learners with their own practices and intentions of use?

To answer these questions, we share research from one teacher and his sixth-gradestudents (11 and 12 years old) as they used iRemix, an online social learning network designed to engage youth in cre ating, sharing, and interacting around multimedia artefacts. We engaged in learning analytics as a way to use log data sets to examine activities on the system over time at the level of individual students and a community of learners. Learning analytics is defined as collecting, analyzing, and reporting data about learner actions and interactions within their specific context, with the intention of better understanding and optimizing learning environments (Siemens \& Long, 2011; Siemens, 2012). A sub-strand of this emerging and increasingly important analysis and design space is social learning analytics, which focuses on interactions between users to highlight potential social learning processes as an important ad dition to more traditional measures of learning activities, such as time-on-task or completion rates (Buckingham Shum \& Ferguson, 2012). This greater attention to sociocultural dimensions of the individual users in the system and the learning processes between them has the potential to add to the 
(2016). Revealing opportunities for $21^{\text {st }}$ century learning: An approach to interpreting user trace log data. Journal of Learning Ana lytics, 3 (2), 37-87. http:// dx.doi.org/10.18608/jla.2016.32.4

"pedagogical and ethical integrity" of the analysis of user log data (Buckingham Shum \& Ferguson, 2012).

In this paper, we start with theoretical and design background to position our work, including definitions of 21st century learning, related research looking at opportunities for 21st century learning in K-12 blended learning environments, and the learning and design framework underlying the iRemix platform. We then detail our multiple exploratory methods used to answer the primary research questions. Results are laid out in three parts addressing focal questions through different levels of analysis. First, we share a rich qualitative case of the face-to-face learning environment, including the school, the teacher, and the classroom over the course of the year. Second, grounded in the qualitative context, results of student log data analysis are presented and triangulated with self-report survey data to look at patterns within one unique community of learners. Third, we return to qualitative data to look deeply at two student learners within the community who exhibited different levels of activity on the syste $m$ to better understand log patterns. We close with a discussion of results, and plans for future work.

This paper contributes to existing research in $\mathrm{K}-12$ blended learning environments, and shares an exploratory approach for understanding activity in online learning platforms in ways that go beyond traditional metrics of success. We believe that, although in an early stage, this work has implications for researchers, designers, and educators who strive to support youth from different communities to participate online in becoming 21st century learners.

\section{BACKGROUND}

\subsection{Defining 21st Century Learning}

There is widespread acknowledgement both that the rise of computing is resulting in an increase in workforce demand across occupational fields for those who can e ngage in complex human thinking and communication, and that our present system of education is not prepared to teach or evaluate these more abstract abilities (Levy \& Murnane, 2004). At the same time, there is less demand for those who perform more procedural content and tool-specific tasks that can be automated. As a result, stakeholders in education and workforce development, including policy-makers (e.g., Pellegrino \& Hilton, 2012; NGSS Lead States, 2013; National Governors Association, 2010) and industry heavyweights (e.g., Partnership for 21st Century Skills, 2011) are working to define, assess, and support devel op ment of aspects of 21st century learning.

Although there is no one definition or agreed-upon taxonomy of 21st century skills and discussions of 21st century learning attend to various components of what this means (i.e., dispositions, skills, orientations, and competencies), there is usually attention to both individual and interpersonal dimensions. The Partnership for 21st Century Skills argues that success is dependent on four broad and transferable skills: critical thinking, communication, collaboration, and creativity (2011). The Assessment 
(2016). Revea ling opportunities for $21^{\text {st }}$ century learning: An approach to interpreting user trace log data. Journal of Learning Ana lytics, 3 (2), 37-87. http:// dx.doi.org/10.18608/jla.2016.32.4

and Teaching of 21st Century Skills project, comprised of international education officials and representatives from leading technology companies, include four strands: 1) ways of thinking (creativity, critical thinking, learning to learn), 2) ways of working (communication, collaboration), 3) tools for working (informational and technical literacy), and 4) living in the world (citizenship, life and career, personal and social responsibility) (Griffin, McGaw, \& Care, 2012). A National Research Council report (Pellegrino \& Hilton, 2012) organizes 21st century skills into three strands of competencies, co mpri sing cognitive (including problem solving and creative ability), intrapersonal (including self-management, intellectual openness, and work ethic), and interpersonal (including sharing knowledge and working with others).

While these efforts have resulted in some inroads to changing standards (e.g., cross-cutting science practices in the Next Generation Science Standards (NGSS Lead States, 2013), longstanding syste ms are difficult to change. We are interested in the potential for $\mathrm{K}-12$ online environments to supplement traditional instruction in order to support the development of 21st century learning. Jenkins and colleagues' (2009) outline of necessities for engagement in informal online participatory cultures, for example, reflects aspects of definitions of 21st century learning outlined above, including willingness to engage in collaborative work, knowledge of how to manage information, self-direction of one's own learning, and building of collective intelligence.

\subsection{Opportunities for 21st Century Learning in Online Environments}

Online education opportunities are increasingly present in the classroom, often positioned as a potential solution to challenges facing contemporary formal education, such as limited space, prohibitive costs, and issues related to accessibility and equity. A 2009 report estimated that $75 \%$ of public schools had one or more students enrolled in a fully online or blended course, and $66 \%$ estimated that the ir onlin e offerings would grow (Allen \& Seaman, 2008). In 2014, an estimated $\$ 21$ billion of the funds spent in K12 schools were earmarked for technology and $63 \%$ of US districts reported contracting with vendors of online courses (Burch \& Good, 2014).

Less is known about the impacts these opportunities have on young learners. As schools continue to adopt online learning practices and technologies, there is an ongoing effort to define and classify the variety of ways that Internet-enabled collaboration, communication, creativity, and accessible information are changing the state of education (ACCI NSF, 2011). A report issued by the US Department of Education found a dearth of rigorous, published research studies on the effectiveness of online learning environments for K-12 education (Means, Bakia, \& Murphy, 2014). That report includes a metaanalysis of 51 empirical studies of online learning that showed that students in online learning conditions performed better than those receiving face-to-face instruction, but caution was advocated in interpreting results because of the extreme variability between platforms, ages, context, time, and perhaps most importantly, definitions of learning. 
(2016). Revea ling opportunities for $21^{\text {st }}$ century learning: An approach to interpreting user trace log data. Journal of Learning Ana lytics, 3 (2), 37-87. http:// dx.doi.org/10.18608/jla.2016.32.4

There is growing consensus that online and blended learning implementations require new strategies, policies, and tools to be successful, and new ways to measure success. The National Science Foundation Advisory Committee for Cyberinfrastructure calls out the need for a "revolutionary" approach to paradigmatic shifts and systemic structural reform as well as more immediate changes to technologybased curriculum to meet current workforce standards (ACCI NSF, 2011). Researchers argue that educators must find ways to utilize technology as more than just a way to deliver curriculum, engaging it for critical, creative, and social purposes that leverage capabilities (Buckingham, 2007). We see an opportunity to reframe and supplement how we look for evidence of learning and success in formal environments by attending to skills and practices that have been identified as cutting across different content areas and grade levels, those defined as part of the corpus of 21st century learning, and by building on what we know about learning in informal online spaces.

\subsection{Evidence of 21st Century Learning in Online Social Networks}

Though the specific features of social network sites vary, they have been defined as web-based services that allow individuals to construct a public or semi-public profile within a bounded system, articulate a list of other users with whom they share a connection, and view their list of connections and those made by others in the system (Boyd \& Ellison, 2007).

Existing studies of learning and developmental affordances of common social network sites without a particular topic or focus beyond connecting to others, such as Facebook and MySpace, suggest relationships between usage and some cognitive skills, such as developing technological fluency (Ahn, 2013) and digital literacies (Greenhow \& Robelia, 2009a), and intrapersonal and interpersonal capacities, such as trying out new socially responsible identities (Greenhow \& Robelia, 2009b), and communicating with other students around academics (Salaway, Caruso, \& Nelson, 2008; Selwyn, 2009).

Online communities can also be more focused, comprised of a blend of expert and novice participants who come together around a common interest or pursuit, such as those formed around massive multi player online games, online forum health and support communities, and how-to maker groups. Notions of learning in online networked spaces build on the work of Lave and Wenger (1991), who defined a community of practice as a group of people with a common profession or craft, where learning occurs as a social process as knowledge is co-constructed by members sharing information and experiences. For youth, examples include the Scratch online community, an online introductory programming environment where kids can create, share, and remix projects, and Project Noah, an online citizen science site with classroom components allowing youth to upload species observations as photog raphs and GIS information and share results and get feedback. Often, these platforms incorporate social network features to support these peer-to-peer interactions. The also include me mbership and some formal policies around usage. 
(2016). Revea ling opportunities for $21^{\text {st }}$ century learning: An approach to interpreting user trace log data. Journal of Learning Ana lytics, 3 (2), 37-87. http:// dx.doi.org/10.18608/jla.2016.32.4

Studies have identified youth using online communities in ways that connect with 21st century learning as they share their ideas and work with a community, learn from others, find learning resources, establish partnerships, and make choices about theirfuture. An ethnographicstudy of yo ung pe ople's use of digital media found that through participation in online communities or special intere st groups, young people were learning new skills, assuming public roles as digital artists and producers, editors, and directors, developing important learning relationships, and making sense of complex ideas (Ito et al., 2009). In another study, case studies of girls highly engaged in online communities revealed both the development of technological literacy and new identities such as global citizenshi p (Guzzetti, 2006). A study of participants in online gaming communities found individuals developing high -level collaboration skills, and taking new knowledge learned within the gaming community back into their real-world employment (Walter, 2010). Research of Flickr participants, an online photographysharing site, showed individuals learning from each other and creating new meanings together for their collective photography practices and the normed behaviour practices on the site (Robbie \& Zeeng, 2008).

In the following section, we share the iRemix platform design, which was developed intentionally to capitalize on the engagement of youth in informal social learning networks and online communities.

\section{PLATFORM DESIGN: IREMIX}

Since 2004, the Digital Youth Network (DYN) has developed formal and informal learning opportu nities and environments for urban youth, focusing on the development of traditional and digital media literacies, and a related community of practice (Martin \& Pinkard, forthcoming; Barron, Gom ez, Pinkard \& Martin, 2014). DYN programs and platforms are offered in formal school classroom instruction and informal community spaces, such as afterschool and libraries. Building on a learning ecologies framework that envisions learning as an ongoing process (Barron, 2004; 2006), DYN utilizes te chn ol ogy infrastructures to engage youth in productive learning experiences across physical spaces of home, school, and community.

iRemix (see Figure 1) is a DYN-developed closed social network designed for middle- and high-schoolaged youth (eleven-to-eighteen year olds) used across the city of Chicago in formal and informal environments. The site was designed to foster the development of youth media projects and to connect a community of learners, including students and educators, around these creative artefacts. Although iRemix can be used in different ways, with different content focus, in different sorts of environments, the overarching learning goal for the platform mirrors that of the DYN program, to support the development of digital media citizens through production, reflection, critique, and communication (Barron, Gomez, Pinkard, \& Martin, 2014). The purpose of the iRemix site aligns with research suggesting that the future of media and information is in the hands of youth who have the power to create and share their own perspectives (Gauntlett, 2012). 
(2016). Revealing opportunities for $21^{\text {st }}$ century learning: An approach to interpreting user trace log data. Journal of Learning Ana lytics, 3 (2), 37-87. http:// dx.doi.org/10.18608/jla.2016.32.4

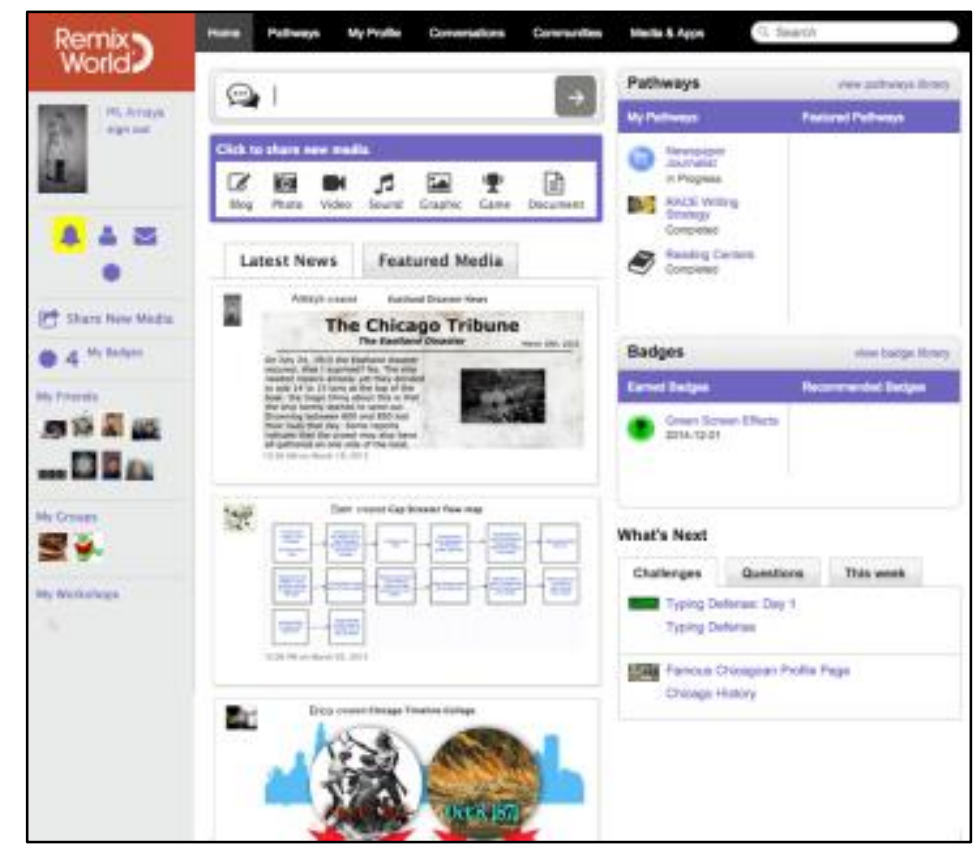

Figure 1: Amaya's home page of the iRemix site.

The iRemix platform provides a classroom, school, or program the ability to customize a closed social learning network instance and to control who can access it. Each instance has its own URL, logo and colour scheme, and learning activities. We define iRemix as an online social learning network, a Webbased environment that uses features of social network sites and learning management systems to support and develop an online learning community and the individual participants with in it (see Figure 2). Within the environment, the individual learner interacts with the system and the embedded resources within that system (youth-system interactions) and also with other learners on the system (youth-adult educator interactions and youth-peer interactions). In this section, we look at how features of learning management systems (integrating more formal learning approaches) and social networks (integrating informal learning approaches) were intentionally used in iRemix to support DYN programmatic goals, including development of technological literacy through creative production, community participation through communication and critique, and self-directed learning through utilizing networked resources and monitoring progress. 
(2016). Revea ling opportunities for $21^{\text {st }}$ century learning: An approach to interpreting user trace log data. Journal of Learning Ana lytics, 3 (2), 37-87. http:// dx.doi.org/10.18608/jla.2016.32.4

Participants have their own profile page, can link to others, and can see these links.

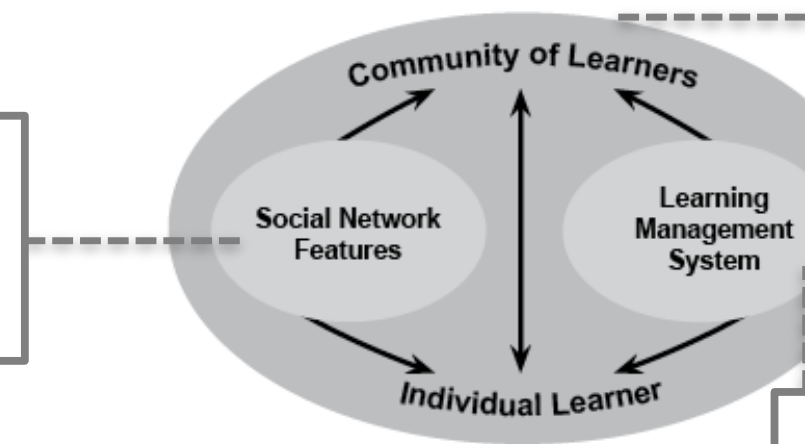

Educators prompt, organize, scaffold, monitor, and assess work and assignments.

Figure 2: Annotated representation of the multidirectional learning supports in iRemix.

\subsection{Using Learning Management Features to Support Project-Based Instruction}

Learning management systems (or course management systems) refer to computer-based systems designed to assist instructors and learners in the management and administration of course dissemination and participation, particularly distributing course content and tracking student performance (Ullman \& Rabinowitz, 2004). Teachers can organize their lessons, upload and distribute content, facilitate student collaboration through forums or wikis, connect with other teachers, parents, and administrators, conduct assessments, and track and analyze classroom reporting such as grades, attendance, homework, etc. Examples in K-12 include adaptable open-source packages such as Google Classroom, EdModo, and Moodle and proprietary systems such as Blackboard Learn and Pearson SuccessNet. Through learning management systems, educators contribute the content that their students will engage with and can structure how and when that will happen, usually with in a bou nded time period, such as a course or an academicyear.

iRemix purposefully incorporates features of learning management to support proje ct -based learning through artefact-driven curricula. DYN's focus on project-based learning builds on the idea that youth should be creators, not simply consumers of technology, and the site is structured around the submission of digital artefacts in multimedia formats (including images, video, audio, and text documents). Recent research suggests that engagement in creative production activities can help nurture a range of 21st century skills such as an innovative mindset and a sense of creative self-efficacy (Barron \& Martin, 2016; Blikstein, 2013; Vossoughi \& Bevan, 2014), the development of confidence with tools, a sense of ability in generating novelideas, skills in using networked resources for learning, and a willingness to engage in rounds of revision and troubleshooting (Barron, Gomez, Pinkard, \& Martin, 2014; Ito et al., 2009).

Specific learning management features that allow educators to guide the work that youth engage in on the platform include templates for scaffolded learning pathways, guiding educators to upload sequences 
(2016). Revea ling opportunities for $21^{\text {st }}$ century learning: An approach to interpreting user trace log data. Journal of Learning Ana lytics, 3 (2), 37-87. http:// dx.doi.org/10.18608/jla.2016.32.4

of assignments culminating in a digital media submission (Madison-Boyd \& Steele, 2015), and assessment mechanisms such as rubric ratings that align to the requirements and learning dimensions set in the learning pathway activity formation. Within learning pathways or other one-off calls for student work such as through a blog post, educators can build in learning supports for students to enable more independent progress toward project completion, such as embedded and linked resources, how-to guides, and clear assessment dimensions. Youth learners can navigate through available learning pathways or one-off assignments, upload their work to the system within the calls for particular activities, and directly ask questions about the assigned work through messaging. Youth and e ducators can review submissions and participation by looking at individual student progress along a pathway and through individual portfolios of work.

\subsection{Using Social Network Features to Support Community Development}

While adult educators hold key positions in the iRemix network as they organize, structure, and facilitate learning in the online space, the system is also designed to foster a learner-driven community that reflects youth voice and interests. Importantly, students can access the system out of class and on the ir own time. One design decision was to al low youth to post digital artefacts in various spaces on the site, at any time, not just as submissions to educator-driven prompts. Features allowing youth to con tribute individual ideas and work outside of assignments include status updates, comments, blogs, debates, and forums. All media submissions can be identified by the user as original (created by the user) or not. Additionally, incorporating ways for youth to interact with each other around their work was critical as was support for ways for youth to connect to adult mentors and educators outside of face-to-face time, building on the importance of peer-to-peer and youth-mentor supports and interactions that were critical to the success of DYN in face-to-face settings (Barron, Gomez, Pinkard, \& Martin, 2014).

Social network features were intentionally built into iRemix to cultivate a community of learners who shared an interest in and practice of media project creation and development. Users are able to create a profile page, link to peers through shared classes and friendship nominations, and view others on the system. Individuals on the system and their work are identifiable and observable, regardless of expertise or age. Users can form groups and start discussions around shared interests, problems, or practices, including those not formally part of the program curriculum. Multiple methods for one-to-one and oneto-group communication are available to educators and youth on the system, including private messaging, commenting, debates, forums, and discussion threads.

Below, we summarize the primary learning activities the system was designed to support and the corresponding iRemix features (see Table 1). For the sake of clarity, we organize these features in terms of discrete intentions, but many activities and features are interconnected, and in fact the redundancy and interwoven nature of the site is intentional to allow multiple entry points to participation. 
(2016). Revealing opportunities for $21^{\text {st }}$ century learning: An approach to interpreting user trace log data. Journal of Learning Ana lytics, 3 (2), 37-87. http:// dx.doi.org/10.18608/jla.2016.32.4

Table 1: Specific iRemix features mapped onto youth learning intentions.

\begin{tabular}{lll} 
Intention & Features & Screenshot of feature \\
\hline $\begin{array}{l}\text { Create and } \\
\text { sharework and } \\
\text { ideas }\end{array}$ & $\begin{array}{l}\text { Multimedia } \\
\text { submission } \\
\text { formats (text, } \\
\text { video, sound, } \\
\text { games, photos, } \\
\text { designs) in } \\
\text { multiplespaces on } \\
\text { the site }\end{array}$
\end{tabular}
Description

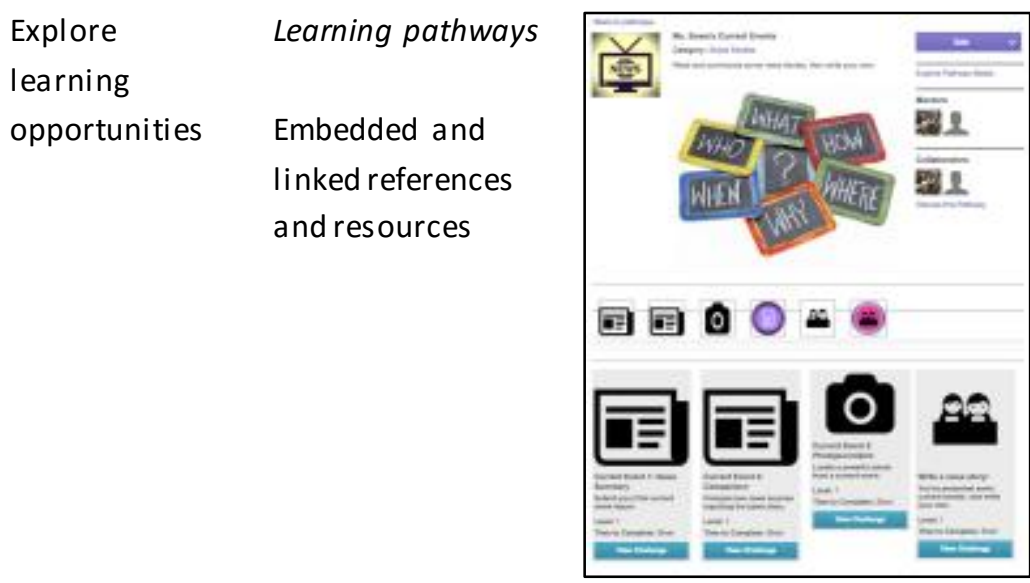

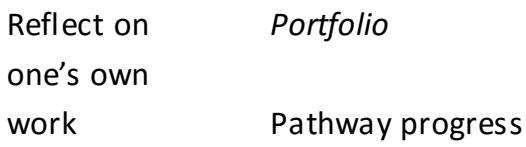

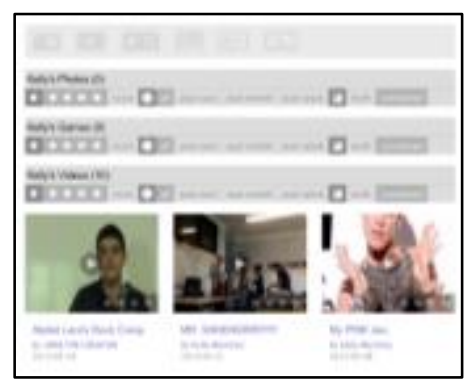

Develop Profiles

identity as a

creator
Status updates
Production of digital media artefacts, revising based on review of work and external feedback, and submission online. Expression of ideas through multimedia and authentic audience sharing. Work can be submitted within formal learning pathways or in response to adult-educator prompts for submission, as well as at any time in other spaces, such as the activity feed, forums, or groups.

Seeking out ideas and resources for learning and creation, including those related to required assignments and opportunities for going broader or deeper in a certain area. Pathways also include exemplars submitted by others, which can be explored to generate new ideas.

Portfolios a re public, displaying all work submitted by one user, grouped by media type.

Pathway progress visualizations show completion and work yet to do, supporting learners in planning and reflecting.

Each user has a public, editable profile page including username, image, and space to tell about themselves through text, images, video, and HTML formatting. It is linked to portfolios of work.

Brief status updates can be entered 
(2016). Revea ling opportunities for $21^{\text {st }}$ century learning: An approach to interpreting user trace log data. Journal of Learning Ana lytics, 3 (2), 37-87. http:// dx.doi.org/10.18608/jla.2016.32.4

$\begin{array}{ll}\begin{array}{l}\text { Observe and } \\ \text { connect with }\end{array} & \begin{array}{l}\text { Visible links to } \\ \text { other users }\end{array} \\ \begin{array}{l}\text { others engaged } \\ \text { in similarwork }\end{array} & \text { Groups }\end{array}$

Activity feed

Communicate
with others
around work
and ideas

Critique through
ratings
Comments

Private messaging

Forums
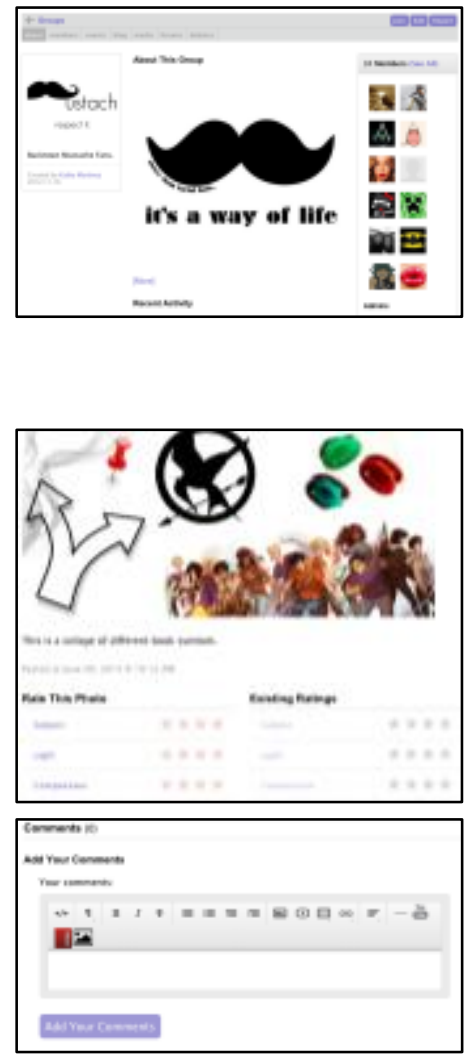

from the home page and are broadcast to the site activity feed.

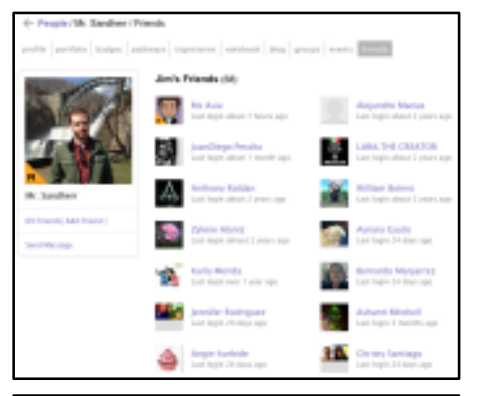

There are multiple ways to view individual participation as part of a larger community of practice that includes adult educators and peer experts and novices, with the ability to identify friends and form and join groups based on special interests. Clicking on visible us ers leads di rectly to their profile page and portfolio of work.

The activity feed shows a live update of activity on the site, including who and what, allowing users to open individual profiles and/or view a related artefact.

Various methods and modes to express opinions, critiqueideas, develop evidence-based arguments, and widely broadcastideas, both privately to individuals and publically to the entire network. These multiple entry points for communication are intended to support learners in direct interaction with others on the site, specifically around work and ideas. Examples include ratings systems to allow users to rate the projects of others using rubrics or the comment function.

\section{METHODS}

Goals for this exploration of user trace log data were twofold: first, to interpret raw log data in ways that felt authentic for the unique contexts of use, allowing for interpretation by educators and DYN learning designers that could lead to changes in design and practice, and second, to contribute to larger conversations about using learning analytics to explore the potential for 21st century learning in online spaces. We use a "bottom up" approach to study a sociotechnical system, looking at a set of automated 
(2016). Revea ling opportunities for $21^{\text {st }}$ century learning: An approach to interpreting user trace log data. Journal of Learning Ana lytics, 3 (2), 37-87. http:// dx.doi.org/10.18608/jla.2016.32.4

logged actions for a smaller set of users combined with qual itative data from the environment to better understand variation in patterns of use and intentional ity about, or barriers to particip ation.

\subsection{Participants and Local Context}

We report on one English Language Arts teacher, Mr. Kellog, who used iRemix with his sixth grade students ( $N=53$ ) over six months from January to June 2014. Kellog taught in a $\mathrm{K}-8$ public school serving 500 students. The school was located on the far west side of Chicago, and although the school was open to anyone within city limits through a lottery system, it drew the majority of its students from the predominantly Latino local community. The student sample in this study reflected the larger school demographics, and included $47.2 \%$ girls and $52.8 \%$ boys, with $89 \%$ self-reporting as Latino, $6 \%$ black, $2 \%$ white, and $2 \%$ Chinese. Over three-quarters of these students (83\%) reported Spanish-speaking households. Home technology access and activities for this sample looked similar to teens ge ne rally in the US (Lenhart, 2015). Most (85.1\%) had their own computer at home and almost all (96.2\%) reported home Internet access, although only about half (48.9\%) said that it worked consistently. The majority of students regularly (more than once a week) played digital games (77.6\%), used a social network site (75.5\%), looked for information online for homework $(69.4 \%)$, and used the Internet to look for information related to their intere sts or hobbies (62.5\%).

\subsection{Data Collection and Analytical Strategies}

Our first research question asks how we can identify evidence of opportunities for 21st century learning in log data of user traces. Our second question asks how we can understand activi ty patterns in different communities of learners with their own practices and intentions of use. In this exploratory work, our data collection methods drill down from the system level to the individual to better understand the learning environment from various perspectives, helping us to interpret log data. To answer the first question, we first collected iRemix user trace log data from the student cohort and engaged in le arning analytics, applying an exploratory analytical process and framework for identifying evidence of potential opportunities for 21st century learning. We then used self-report student survey data to explore correlations. To answer our second question, grounding what we saw and continuously refining our interpretation of results, we also engaged in extensive qualitative case studies of the classroom, teacher, and youth learners. Below we detail these three data collection strategies and analytical approaches.

\subsubsection{Creating a framework of interpretation}

In addition to the data generated through general use of the iRemix platform, a separate data table of records of iRemix trace logs is maintained. The creation of records in the trace logs database is triggered by user actions and certain system events determined by the DYN technical develop ment team to be of interest (e.g., posting updates to the activity feed). These have evolved along with the system and the organization over time. At the time of this study, there were 158 unique trace log records. A unique log record is defined by the action $(n=40)$ and the type of object involved in the actions $(n=38)$. Examples of 
(2016). Revea ling opportunities for $21^{\text {st }}$ century learning: An approach to interpreting user trace log data. Journal of Learning Ana lytics, 3 (2), 37-87. http:// dx.doi.org/10.18608/jla.2016.32.4

actions include login, read (looking at work and the profiles of individuals), create (posting media or starting a blogpost), comment (adding a comment to posted work or a discussion), and rate (formally assessing posted work). Examples of types of objects connected to actions include blogpost, video, photo, user, and group. For example, the action-type read-photo is a unique type of logged record, and is generated when the user clicks an interface control (i.e., a button) in order to view a photo. The action-type comment-blogpost indicates the user posted a comment in response to a blog post. In addition to the action and type, the trace logs capture other fields including timestamp, the userID of the person who triggered the action, the artefactID of any specific artefact (e.g., which photo was viewed). Some types of logs include fields containing relevant content, such as the title of a posted artefact and the text entered as a comment.

Log data was collected in Kellog's instance of iRemix (users included 1educator and 53 students) from January 2014 through the end of the school year in June ( $n=25,746$ user trace logs). Transformation of log data sets was achieved to clear the data of irrelevant activity (i.e., researcher visits to the site, or log data that was misrepresented or duplicated at the point of capture), and various exploratory analyses were performed on the dataset, including Tableau visualizations and SPSS descriptive and correl ati onal analysis to look for patterns. This cycle of pattern finding and data cleaning allowed us to finalize a dataset and prepare forfurther transformation and analysis. The strategy for analysis, specifically how we operationalized the raw log data to reflect clusters of log activity representing potential opportunities for 21st century learning includes 1) conceptual framework and rationale, 2) technical iRemix configuration, and 3) creating a schema of mapping raw log data onto an operationalized learning framework. We consider this work to align with definitions of social learning analytics (Buckingham Shum \& Fergusson, 2012).

Mapping iRemix logged actions onto 21st century learning themes and DYN intentions. Our first step was to conceptualize how the actions captured in the iRemix system map onto the broader types of 21st century learning activities that the DYN program and platform were designed to foster - creative production, self-directed learning, and social learning. Moving between the actions collected by the system (the data collected) and the learning intentions behind the design of the syste $m$ (the intended feature usage based on prior DYN goals and prior work, as well as what we know about potential learning outcomes afforded by learning management systems and social learning networks), our team of researchers, with input from DYN learning designers, technical developers, and educator practition ers, developed a framework to operationalize actions logged on iRemix as evidence of opportunities for creative production, self-directed learning, and social learning (Table 2). We consider these to be human capacities necessary for productive participation in the 21st century, and while they do not represent all areas of 21st century learning, they do align with parts of current definitions as laid out in the Introduction to this paper. Critically, this framework is exploratory - it is not meant to imply that activity on the system is evidence of learning, but rather reveals certain activity as evidence of a learning opportunity. This work employs the strategy of first looking for evidence of the situational opportunities 
(2016). Revea ling opportunities for $21^{\text {st }}$ century learning: An approach to interpreting user trace log data. Journal of Learning Ana lytics, 3 (2), 37-87. http:// dx.doi.org/10.18608/jla.2016.32.4

for learning in observed online behaviours (i.e., counting opportunities when learning was possible, not that it actually occurred) (Reich, Murnane, \& Willete, 2012) prior to pursuing alignment of action and learning outcome.

Table 2 lays out the framework of iRemix opportunities for 21st century learning, including the three focal learning themes, 11 intended learning opportunities related to this theme, and the corresponding logged actions on the iRemix system. We envision these elements as the building blocks of usage of the system, the language that can let us look for patterns in this exploratory work. In this in terpretive framework, careful attention is paid to iRemix as a social learning network; in other words, the meaning of the logged action was dependent on the role of both the actor and the recipient.

The project-based focus of DYN is based on research, suggesting that engagement in creative production activities, including cycles of feedback and revision, can help nurture 21st century skills such as creativity, technical self-efficacy, and working through complexity (Blikstein, 2013; Vossoughi \& Bevan, 2014; Barron, Gomez, Pinkard, \& Martin, 2014). Online profiles have been shown to promote individual visibility on a network (Girgensohn \& Lee, 2002). As such, we classify log actions of Edit own profile page, Post created media (original), Edit own work, and Resubmit work as opportunities for creative production, as youth work to create and revise digital media artefacts and develop their public identity as a creator online.

Actions related to the learning management features in the system are intended to provide opportunities for youth self-directed learning, specifically allowing youth to look for new opport un ities they are interested in, use embedded and linked digital learning resources, and seek support from an educator by asking a direct question about an activity. The learning pathway progress visualizations provide students with a tool to support self-regulated learning as they look at their progress and plan out what they have to do next (Dabbagh \& Kitsantas, 2012). As such, we classify logs of View own pathway progress, Post question to educator about assignment, View potential activity, and Open activity resource as opportunities for self-directed learning.

To look at opportunities for social learning, we specified those features identified as potential learning interactions with others around work, including looking at the work of individuals to get new ide as for their own work (Peppler, 2013), participating in interest-based communities (Jenkins et al., 2009; Ito et al., 2009), exploring communities and individuals to see who is in the network, what they are interested in, and what they are doing, and actively communicating through comments on work (Berlanga et al., 2007) or ideas, or more formal critiques (Barron, Gomez, Pinkard, \& Martin, 2014). We classify log actions of Create new group, Join existing group, Open work of user (peer or educator), Open profile of user, Open portfolio of user, Open group, Open forum, Comment, and Provide critique rating as opportunities for social learning. 
(2016). Revealing opportunities for $21^{\text {st }}$ century learning: An approach to interpreting user trace log data. Journal of Learning Ana ly tics, 3 (2), 37-87. http:// dx.doi.org/10.18608/jla.2016.32.4

Table 2: iRemix 21st century learning opportunities framework.

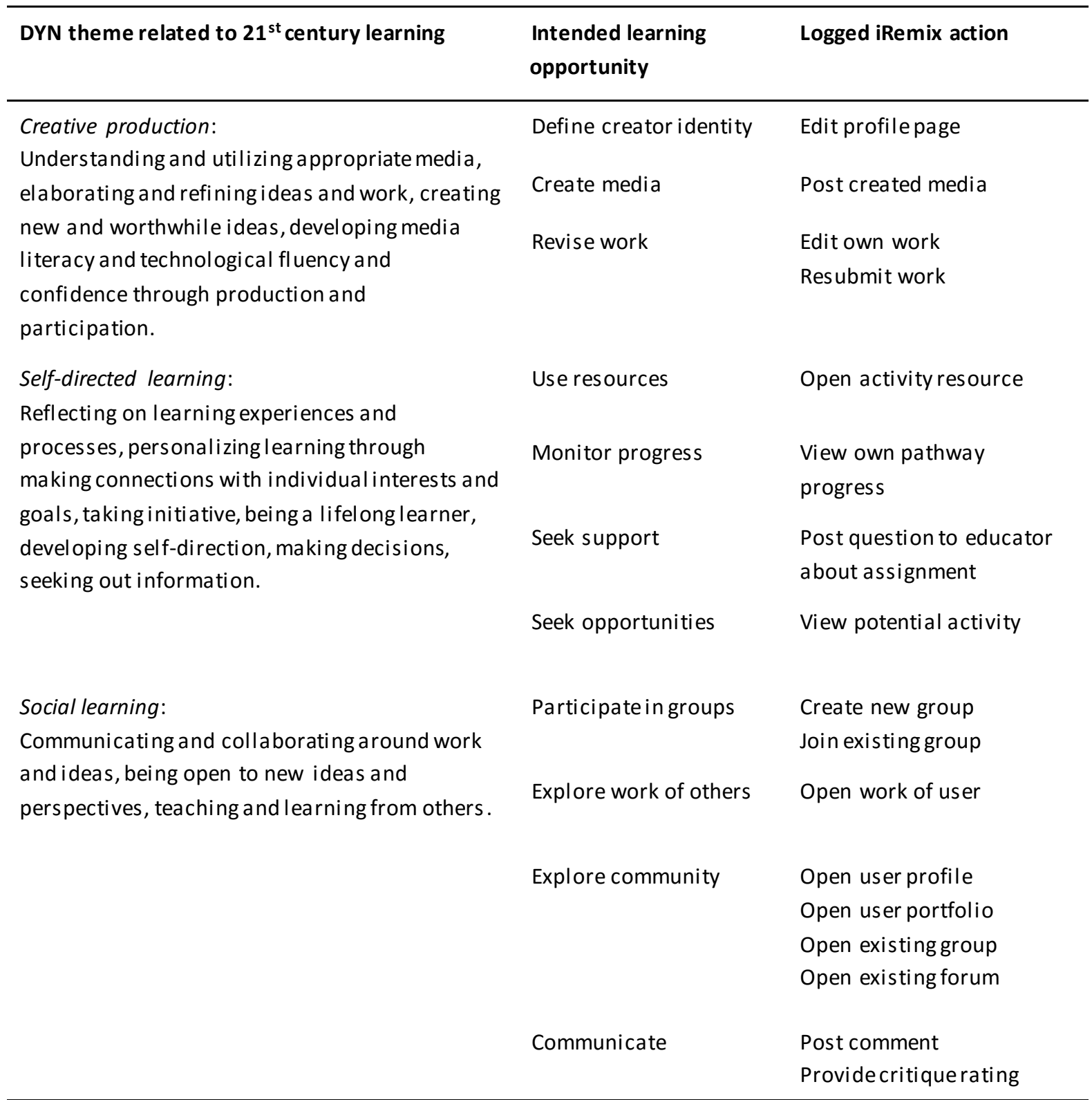

Streamlining technical iRemix configuration and coding process. Next, we developed a technical configuration of iRemix that permitted researchers to access trace log data, implemented the coding framework, and produced a database of coded logs that can be used for data analysis and visualization. Figure 3 provides a simplified overview of this configuration. A cloud-based production server provides storage and computing for the iRemix platform. The platform itself contains various data tables typically required of such social network applications, such as data related to instances, site customization settings, users and accounts, posted content, groups, commenting, as well as data related to more 
(2016). Revealing opportunities for $21^{\text {st }}$ century learning: An approach to interpreting user trace log data. Journal of Learning Ana lytics, 3 (2), 37-87. http:// dx.doi.org/10.18608/jla.2016.32.4

specialized features such as debates, ratings, challenges, and pathways. This data is generated and stored as users access and interact with the system.

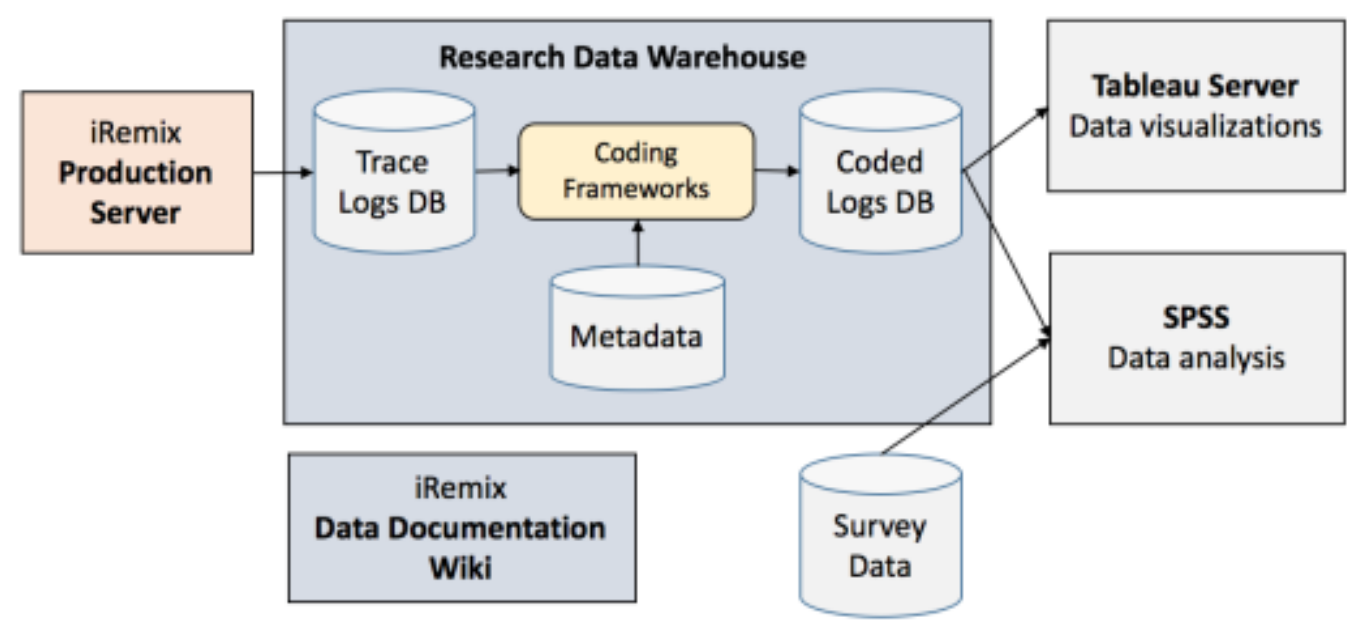

Figure 3: Technical configuration of iRemix enabling log coding.

To serve our research and design needs in analyzing and creating visualizations based on the trace logs, we established a Research Data Warehouse, separate from the iRemix platform production server, to house the trace log data and other data not generated by the iRemix platform but needed for analysis and visualization (such as the 21st century learning opportunities framework). This Research Data Warehouse, also stored on a cloud-based server, is populated through nightly routines that copy new trace log data from the production server. This separation between the production server and the Research Data Warehouse allows for controlling access to iRemix data by instance and reduces que ries to the production server that may negatively impact platform performance.

This process of triggering the creation of trace logs, determining which fields and values are included in the logs, and tracking the unique types of logged actions is negotiated among the iRemix programmers, researchers, and designers. As new features are added, or as features are altered, decisions must be made about how to add to or modify the creation of trace logs and how they are coded. To support collaboration and communication around data documentation, we created a wiki for internal staff as well as external stakeholders (such as administrators and researchers using their own iRemix instances). The wiki provides an index of key data tables linked to descriptions of fields, value types, dimension tables, known issues, examples, and other annotations.

Automating coding of raw trace logs to the 21st century learning opportunities framework. The database of trace logs (action-type) described earlier are the raw logs produced by iRemix. That is, they are meant to provide the base level information describing the actions taken. While the data provided in 
(2016). Revealing opportunities for $21^{\text {st }}$ century learning: An approach to interpreting user trace log data. Journal of Learning Ana lytics, 3 (2), 37-87. http:// dx.doi.org/10.18608/jla.2016.32.4

these logs has utility for capturing user behaviour, we use coding frameworks to further categorize logs. These frameworks represent our developing theoretical understandings as they emerge from ongoing research and make explicit connections to the types of actions logged in iRemix. In this paper, we focus on the 21st century learning opportunities framework to better understand the online activities of youth. This is part of our larger work to understand interactions and learning on the iRemix site (e.g., coding the learning support actions of adult educators; see Nacu, Martin, Pinkard, \& Gray, 2014). The se frameworks are stored as databases to translate raw logs to coded logs in the Research Data Warehouse (Nacu, Martin, Schutzenhofer, \& Pinkard, 2016).

Figure 4 provides a summary of the coding process. For actions made by youth learners, our objective is to connect the raw code with an intended learning opportunity and a linked broader theme of 21st century learning to facilitate summary and interpretation. To do this, categorizing student actions first requires coding the logs based on the unique log type (i.e., the action-type, such as comment-video). Next, the coding framework examines who the action was directed towards in order to apply an intended learning opportunity code. That is, the coding framework considers the actor and the recipient of the action. For Example 1 in Figure 4, if a student (the actor) clicks a button to view the posted video (action-type: read-video) of a peer (the recipient), this action will be coded as exploring the work of others, and linked to the higher level DYN learning theme of social learning. In Example 2 in Figure 4, if the log data indicates that the video was created by the user (self) and the action is edit, it will be code $d$ as reflecting the learning opportunity to revise work, which relates to the theme of creative production.

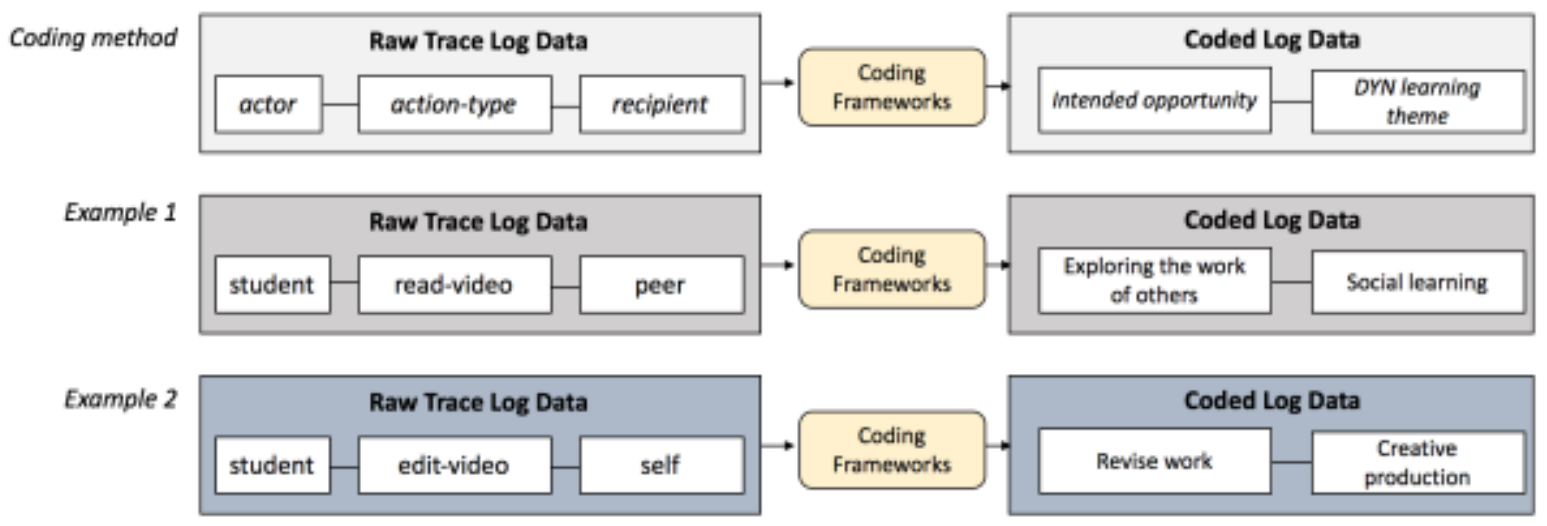

Figure 4: Summary of automated coding of raw trace log data.

While iRemix provides most of the data used in our analysis through the trace logs database, other metadata is used to organize the trace logs. For example, while iRemix in its current configuration organizes user data into instances, it does not store historical classroom roster data. For research purposes, it is important to know how youth learners are associated with individual educators and e ach other, and how those classroom and program rosters change from year to year. While this metadata set 
(2016). Revea ling opportunities for $21^{\text {st }}$ century learning: An approach to interpreting user trace log data. Journal of Learning Ana lytics, 3 (2), 37-87. http:// dx.doi.org/10.18608/jla.2016.32.4

is relatively small, it is part of the configuration that helps to organize the raw logs into the groupings needed for data analysis, reporting, and visual ization.

Once the raw trace logs are coded, this becomes a data source that can be used for analysis and visualization. A dedicated Tableau server connects to the research database and allows for the creation of data visualizations that can be made accessible to various user groups. Tableau was selected as a platform for data visualization and analysis because it allows for a direct connection to the so urce data (via the Research Data Warehouse), allows for quick prototyping and iteration on interactive data visualizations, and provides robust user and group controls for providing access to subsets of data. The coded data logs can also be exported for use in SPSS (and other tools as needed) to be considered along with other data, such as surveys, for quantitative data analysis.

Importantly, user trace log data may not always reflect intentional decisions to click or not click certain areas of the site. Thus, while we are interpreting the absence of data in user logs for a certain area as evidence of the user lacking the initiative to trigger that log, it may rather be that the user did not know how to access or use a particular feature. Similarly, there is a chance that some logs represent parts of a click-through path necessary to get to another intended activity. Through our initial process of meaning making as we refined our framework for 21st century learning opportunities, we tried to minimize these types of clicks. For instance, the log data consisted of an overwhelming number of unique log records of students looking at their own work on the system. On average, $39.52 \%$ of the overall corpus of students' trace actions ( $M=122.57, S D=36.67)$ identified an instance when the user was on a screen that portrayed their own posts. Although self-review is a critical element of online participation and the development of high-quality project-based work, this log skewled us to consider logged actions that were more likely driven by cognizant user choices versus those that could potentially happen as the user was on the way to do something else. Reports of students looking at their own work were generated whenever users navigated to their own profile page or a learning pathway they were working on that day. In other words, this log could be a result of a workflow path click-through as opposed to an intentional discrete activity. These actions, therefore, are not currently part of our 21st century learning opportunities framework. The activity logs we did include in this analysis were considered relatively dependent on some user choice as opposed to a common system path log, although this is not $100 \%$ accurate as users navigate and explore the system in their own unique ways.

\subsubsection{Correlations in online activity with measures of 21st century learning orientations}

To further explore the authenticity of using log data to identify evidence of potential opportun ities for 21st century learning, we collected self-report survey data from the student cohort $(N=53)$. Metrics included those used in previous studies of youth orientations and activities related to 21st century learning (Barron, Walter, Martin, \& Schatz, 2010; Barron, Gomez, Pinkard, \& Martin, 2014; Barron \& Martin, 2016). The survey used Likert-response items, checklists, and rating scales covering the mes of access to technology; prior experiences with digital learning; self-reported interest, confidence, and valuing of technology; plans for the future; and technology social learning network (see Table 3). 
(2016). Revea ling opportunities for $21^{\text {st }}$ century learning: An approach to interpreting user trace log data. Journal of Learning Ana lytics, 3 (2), 37-87. http:// dx.doi.org/10.18608/jla.2016.32.4

Questions focus on technology and digital media learning in particular given the content focus of DYN programming. Surveys were administered near the end of the school year (May 2014) during class time, and took approximately 20 minutes (ranging from 14-27) to complete. Importantly, these surveys we re not meant to imply that youth had developed certain dispositions as a result of their online activities, or vice-versa; they were rather to explore potential correlations between our log data framework analysis and exploratory self-report metrics used in prior studies.

Table 3: Survey measures.

Home access

Regular online hobbies

Creative selfefficacy

Confidence with technology activities

Possible technologyrelated jobs for the future Navigating the Internet

Sustained experience with creative production activities
As a proxy for socioeconomic status the survey includes questions about home access to technology - including having their own computer (yes/no) and a working Internet connection - and a checklist format question asking students to indicate their access to specific tools at home: wireless Internet, a printer, a video camera, a di gital camera, a handheld mobile device like an iPad, a smart phone, and a game console. A tools at home measure was computed by summing the number of computers and the number of other tools indicated with a total possible score of 7.

Students indicated how often they participated in four onlineactivities (gaming, social networking, finding information for homework, finding information about a hobby) on an 8 point scale from never to several times a day, and computed a binary measure to indicate regular activities as those they did more than once a week.

A measure of creative self-efficacy uses the average of two ratings of agreement ( $/$ am able to come up with new and interesting ideas and I am able to be creative) on a 5-point Likert scale from 1 (strongly disagree) to 5 (strongly agree); Chronbach's alpha measure of scale reliability=.81.

A measure of technology confidence uses the average of two ratings of agreement ( $/$ am able to do well in activities that involve technology and I am able to learn new technologies) on a 5-point Likert scale from 1 (strongly disagree) to 5 (strongly agree); Chronbach's alpha measure of scale reliability=.78.

Students were asked to rate their agreement about the likelihood of possible future occupations related to technology on a 5-point Likert scale from 1 (not at all likely) to 5 (extremely likely).

Student Internet proficiency was determined based on a survey proxy to measure both effectiveness and efficiency by taking the total of ratings of understanding of 15 Internet terms from 1 (no understanding) to 5 (full understanding), developed and validated to look at online search skills (Hargittai, 2005; Hargittai \& Hsieh, 2012).

Nine technology activities (including programming, creating publications, creating websites, making digital art, robotics, digital movie making, game creation, music production, and developing podcasts) were presented as descriptions of possible products, such as Created a piece of art using an application and Created your own newsgroup blog, or discussion site on the Internet. Students were asked to indicate the number of times they had participated in each from a four-option choice of 1) never, 2) once or twice, 3) three to six times, or 4) more 
(2016). Revealing opportunities for $21^{\text {st }}$ century learning: An approach to interpreting user trace log data. Journal of Learning Ana lytics, 3 (2), 37-87. http:// dx.doi.org/10.18608/jla.2016.32.4

than six times. A breadth score was calculated representing the number of activities a student participated in at least once and a depth score was calculated representing the number of activities a student participated in more than six times, a measure of repeated and sustained engagement across media genres (Barron, 2006; Barron, Walter, Martin, \& Schatz, 2010; Barron, Gomez, Pinkard, \& Martin, 2014).

Technology learning network

Learning from online communities

Social perspectives online
To find out more about a student's network of people they were learning from and teaching about technology, we developed counts of teaching and learning networks. Students were asked to indicate who they were teaching about computing from a list of eight relational categories: mother, father, siblings, other relatives, friends, teachers, other peers, and other adults. We also asked students to indicate who they learned from about computers and technology, from a 3-option choice of not important, somewhat important, and very important, from a choice of their teacher, other teachers at school, adults in an after school program or community centre, mother, father, siblings, friends, other relatives, other adults, and other peers. We totalled the number of categories of people students reported learning from a lot.

A question asked students about the importance of different learning sources, from a 3option choice of not important, somewhat important, and very important. We created a binary measure to determine which students reported learning a lot from online communities.

Students were asked to agree on a 5-point Likert scale from 1 (strongly disagree) to 5 (strongly agree) with statements about their use of the Internet, including an item I feel I've gotten new perspectives on societal issues (issues important to society like poverty, violence, health and safety, civil rights) because of my online activities (Kahne, Middaugh, Lee, \& Feezell, 2012). We created a binary measure to determine which students reported agreement or strong agreement with this statement.

\subsubsection{Developing qualitative portraits of educator and focal-case learners}

To answer our second question, looking to complement and deepen our understanding of our first two analyses, we developed qualitative case portraits of individuals (Barron, Gomez, Pinkard, \& Martin, 2014). This need to take into account the contextual setting has been identified as critical for understanding user trace data in big data (Boyd \& Crawford, 2012). Although our work does not classify as big data, this strategy encourages retaining the authenticity of unique environments of use. To specifically learn more about the individual intentions, goals, experiences, and identities of individual learners within the network, we engaged in interviews with Kellog and a subset of his students $(n=8)$. Students were selected to represent a mix of boys and girls and a range of iRemix engagement, as determined by survey responses about enjoyment (more and less) and use outside of required participation (higher and lower). Interview protocols were ad apted from existing instruments used in prior work (Barron, 2006; Barron, Gomez, Pinkard, \& Martin, 2014), including a learning ecologies interview designed to elicit activities across the contexts of home, school, and community, attending to how the youth used computers and technology in these contexts, and an artefact-based reflection 
(2016). Revealing opportunities for $21^{\text {st }}$ century learning: An approach to interpreting user trace log data. Journal of Learning Ana lytics, 3 (2), 37-87. http:// dx.doi.org/10.18608/jla.2016.32.4

interview using the student iRemix profile and portfolio as a shared reference point to discuss their work, contributions to the site, and plans for learning more. Two teach er interview protocols were developed to reflect on outside interests and activities, professional goals, use of technology in the classroom, and student participation during the year. Interviews were conducted the beginning and end of the school year. Cases use pseudonyms throughout.

\section{$5 \quad$ RESULTS}

We report results in three sections, going back and forth between qualitative understanding of the unique classroom context, community and individual learners, and quantitative log data analysis. In the first section we provide the story of the learning environment and our focal teacher, in the second we present results of log coding and exploratory correlational analysis with survey data, and in the third we locate individual students in the log data and provide a person-centred view of their experience.

\subsection{Learning Environment: Supporting Creative Expression through Digital Production}

Mr. Kellog: I think everything is gearing towards ... just having a wide range of being able to take a simple writing piece or whatever and create a really cool media project in a variety of different ways, through iMovie or stop motion or ... PowToons and Garage Band and all that, so [my students will] go into the high school and be like, all right, I'm going to do this project, and jus $t$ wowing everybody.

In this section, we describe the learning environment and the specific factors influencing student use of iRemix, including the wider school culture and support for technology in the classroom and the teacher's goals and prior experiences.

The school principal and charter administration were very involved with and supportive of technology for learning. In 2012, the school was part of an initiative to connect Chicago Public Schools in underserved neighbourhoods to the US government's Broadband Technology Opportunity Program ( BTOP). As part of a related grant, the school partnered with DYN and received DYN mentor support in middle school English Language Arts (ELA) classrooms and an Apple laptop cart. In his first year of teaching, the year prior to our research efforts, Mr. Kellog was selected by the administration to be one of the school educators involved in this collaboration. ADYN mentorvisited his sixth grade classes once a week supporting students to translate the written work they were doing into multimedia artefacts such as podcasts, videos, and graphics, blending traditional literacy with digital media literacy (Barron, Gomez, Pinkard, \& Martin, 2014). The year following the B-TOP grant, the principal chose to continue the partnership with DYN and DYN offered summer technology programs at the school and an e-fashion afterschool club for girls. The school also added to their own technology offerings including a middle school digital game design elective and a video production afterschool club. The school had a dedicated computer lab, classroom computer clusters, and a regularly updated website that frequently showcased 
(2016). Revea ling opportunities for $21^{\text {st }}$ century learning: An approach to interpreting user trace log data. Journal of Learning Ana lytics, 3 (2), 37-87. http:// dx.doi.org/10.18608/jla.2016.32.4

student media projects. The school administrators promoted data-driven instruction by utilizing a school-wide learning management system that collected, reported, and visualized grades and attendance. School professional development sessions encouraged teacher experimentation with technology tools in their classroom, and introduced new tools, including EdModo, an onlin e platform for teachers often used to assign homework and schedule quizzes.

At the time of this research, Kellog was in his second year of teaching sixth grade ELA and social studies. Despite being a young teacher in his late twenties, he did not use technology much outside of school, did not have a Facebook account or any other type of social media, and before his work with DYN had no experience with creative digital production beyond word processing. Through the collaboration with DYN the year prior to our research, Kellog became engaged in the use of technology for creative production in the classroom. He reflected on his own learning in this area, "Sometimes I'II be up there and, man, [I think], 'Am I really saying this right now?' Talking about iMovies and stuff, so it's cool." He and his students were recognized for their digital production expertise within the school, as Kellog invited teachers and administrators to class presentations and shared exemplary student work through emails and posts to the school website. After his first year of mandatory collaboration with DYN through the B-TOP program, Kellog opted to continue using DYN projects and the iRemix platform with his ELA classes, this time leading the work himself with smaller collaborations with DYN to add additional learning pathways and resources linked to his curriculum.

\subsubsection{Goals and intentions as a teacher}

Kellog felt a responsibility toward his students that went beyond making sure they were proficient in ELA standards. He wanted to make them "ready for the next step... the next step is 7 th grade, but we look beyond that to high school and college" and to "inspire" students to be the "best stude nt you can be." Part of this was to encourage his students to take more control of their own learning, and he described his teaching process as one of "gradual release" from direct instruction to letting students take increasing ownership of their tasks. When asked specifically what he wanted his students to learn, he replied,

I feel like they got iMovie down, which is great, just maybe taking it to a next level or even incorporating some different thinking skills that go into designing, just taking an event piece and creating something really cool ... be more creative with it, which we'd have to real ly think outside the box for it.

The response reveals Kellog's focus on supporting creative expression through the production of digital media, building on the initial work he did with DYN. As such, digital media in his classroom was not often tied to formal grades and assessments, and was positioned as something the entire class, inclu ding the teacher, was exploring together, 
(2016). Revea ling opportunities for $21^{\text {st }}$ century learning: An approach to interpreting user trace log data. Journal of Learning Ana lytics, 3 (2), 37-87. http:// dx.doi.org/10.18608/jla.2016.32.4

I remember our first iMovie. It was just like we'll throw in a text box and write something on it. Then it got more advanced, but I think the very first time we do any of this it's going to be just trial and error. Once they get good at it, that's when we start narrowing down expectations.

In addition to wanting his students to learn the technical skills necessary for contemporary digital production and explore their creativity through multiple modes of expression, Kellog had a communicative goal for the learning and development that went on in his classroom that was part of his desire to invigorate the contributive voice of his focal students:

The culture here is they're very reserved, which allows for easier classroom management, I would say, but a different type of style. You really have to work to get kids to participate and raise their hands ... most of the challenge is getting them comfortable enough to participate and speak in front of the class and share their ideas.

\title{
5.1.2 Goals and intentions for using iRemix
}

Kellog chose to continue using iRemix with his students despite the fact that, like many teachers, he and his students were navigating multiple platforms for management and instruction in his daily teaching. The school student data management system was mandatory and Kellog used it to track student attendance and input formal progress, including grades and test scores. He also used EdModo to dire ct assignments and quizzes to students as one-time events, and allow students to input queries of clarification about content or assignments. While these two systems were used for relatively traditional learning management and instructional practices, Kellog saw iRemix as a space for students to explore and share creative work and ideas. He purposefully did not utilize the more formal learning management aspects of $i$ Remix like assessment of student work. Partly, this was a result of a perceived redundancy, since he had to enter grades in mandatory systems he did not see a reason to al so do it in iRemix, but more importantly, he recognized iRemix as an online learning space that his stu dents we re excited to visit, and he wanted to keep it that way.

\begin{abstract}
A lot of these kids don't have Facebook or whatever, so I think they're all like, they can't wait to get it, this is their opportunity to try it out ... They have a profile, portfolio. They can see each other's work. They can see a whole history of videos, things like that ... They love going on there and checking each other's work out, especially if it has to do with photos ... If I say, "You have free time to go on iRemix," they get excited for that. They feel likeit's more personal.
\end{abstract}

Kellog recognized the system as clearly aligned with his interest in encouraging expression through media artefacts. He appreciated that the system could accept and display different types of media, and that there was a private writing space for cycles of editing and revision. He was particularly interested in student audience as a precursor to constructive criticism and encouragement, which he thought might be easier for the students in his classroom to do digitally. 
(2016). Revealing opportunities for $21^{\text {st }}$ century learning: An approach to interpreting user trace log data. Journal of Learning Ana lytics, 3 (2), 37-87. http:// dx.doi.org/10.18608/jla.2016.32.4

\begin{abstract}
If they're doing a blog, they can post something and then somebody can read that right there online, as opposed to getting up from their desk and then having to look at their notebook, what they're writing. It's a lot easier to see and edit peers' papers and just share ideas. You can comment on videos. If you log in there and a student does a video, another student doesn't have to go walk over to that computer screen. They can stay logged in and can say, "Wow, I really like your video because of this." It takes away that face-to-face interaction, but it allows kids to see their work, get feedback.
\end{abstract}

\title{
5.1.3 Classroom implementation of iRemix
}

During our study, Kellog used iRemix approximately $43 \%$ of the days students were in the classroom ( 49 days over the six-month period). His iRemix instance included seven possible learning pathways. Kell og co-developed five of them with DYN staff to align with his curriculum (e.g., see Figure 5), and the other two were developed by DYN: 1) Introduction to iRemix, designed to get users familiar with the syste $m$, and 2) a pathway focusing on stop-motion animation.

In January, students were formally introduced to the laptops, logged into iRemix with the ir individual usernames and passwords, and started the Introduction to iRemix learning pathway. Kellog's five other pathways were assigned to students over the next six months. The submissions required for completion of these pathways totalled nine media artefacts: three blog posts and two each of videos, images, and audio files. Kellog also posted four assignments as blog posts asking students to submit their work in various ways on the site; submission formats included an online private notebook post, a media post, a blog post, and a comment.

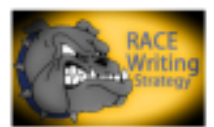

RACE Writing Strategy Category: Language Arts

The activities here will focus on using the RACE method to answer reading comprehension questions. You will be asked to Restate the question, to use the Author's words, to make Connections, and to Explain your answers.
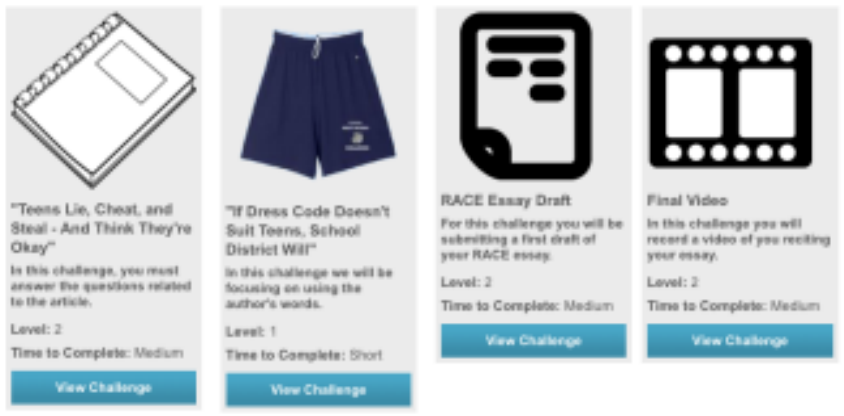

Figure 5: Teacher-developed iRemix learning pathway: RACE Writing Strategy, focusing on the school's writing strategy for standardized testing.

During days that iRemix was a focal activity, Kellog gave his students time in class to go onto the syste m and look at required learning pathways, work on activities, and submit assignments. Studen ts could also 
(2016). Revea ling opportunities for $21^{\text {st }}$ century learning: An approach to interpreting user trace log data. Journal of Learning Ana lytics, 3 (2), 37-87. http:// dx.doi.org/10.18608/jla.2016.32.4

log onto iRemix at home on their own time. The work assigned by Kellog on the system was required, but the work was not formally graded. Instead, he monitored the classroom during iRemix work and presentation days to ensure that everyone had posted. During iRemix work time, and also classroom free time, he encouraged students to look at the posted work of classmates and comment on it. Twice, Kellog also required students to post a comment on the work of another student. He occasionally offered extra credit for original posts beyond requirements, but did not specifically encourage stud ents to begin other learning pathways on iRemix or to review their progress using pathways and portfolio views.

Kellog sometimes blended the digital and classroom learning spaces by projecting the work submitted online on a screen in the physical classroom to showcase different projects and have students present their submitted iRemix work in person. This was linked to his intention of building student confide nce through modes of public contribution and communication:

I also think that community-building within Remix is good, but a lot of what we have troubles with, especially here, is eye contact, face-to-face interaction, speaking loudly, speaking in front of the class, presenting, which we went over. A lot of the projects are, they write this great piece on Remix and then they upload it, but I want them to speak in front of the classroom.

This rich description of Mr. Kellog's intentions and classroom practices allows an additional lens with which to interpret quantitative results. In the next analysis section, we present the automated log data collected from the 53 sixth graders working in this learning environment over the course of six months.

\subsection{Student Learners: Evidence of Opportunities in Student Traces}

The students used the system an average of 52 days ( $S D=9.34)$, with individual students ranging from 37 to 89 days, during the six-month study. They logged into the system an average of 70.57 times ( rang ing from 41 to 129, SD=19.48) and initiated an average of 313.26 logged user trace actions (ranging from 130 to $488, S D=91.91$ ). This variability suggested some level of student-initiated use of the system as opposed to uniform classroom participation. In this section, we apply our framework of 21st century learning opportunities to these logged student user traces (see Table 2).

Table 4 shows the average counts, and minimum and maximum counts for individual students, of the 11 learning opportunities we were looking for, as calculated from automated coding of the individual user trace log actions in the iRemix system for each student over the course of the study. There was a high frequency of activity around youth-created artefacts, including posts of original media and students looking at the posts of others on the system. There were al so frequent counts of explorations of pe ople and activity opportunities on the system, and evidence of communication with others. 
(2016). Revealing opportunities for $21^{\text {st }}$ century learning: An approach to interpreting user trace log data. Journal of Learning Ana lytics, 3 (2), 37-87. http:// dx.doi.org/10.18608/jla.2016.32.4

Table 4: Descriptive statistics of opportunities for 21st century learning, as coded from user trace log data.

Activities logged for learning

\begin{tabular}{lllrrrr} 
opportunity & $\boldsymbol{M}$ & $\boldsymbol{S E}$ & Median & \multicolumn{1}{c}{$\boldsymbol{S D}$} & Min & Max \\
\hline Create media & 39.25 & 1.40 & 38 & 10.22 & 21 & 62 \\
Explore work of others & 35.98 & 2.25 & 35 & 16.42 & 10 & 101 \\
Seek potential activities & 26.70 & 0.99 & 26 & 07.18 & 15 & 48 \\
Explore community & 25.53 & 3.74 & 13 & 27.19 & 0 & 130 \\
Communicate & 22.22 & 1.48 & 21 & 10.80 & 8 & 65 \\
Define creator identity & 21.62 & 1.67 & 20 & 12.15 & 5 & 64 \\
Revise work & 16.96 & 1.06 & 16 & 7.74 & 2 & 35 \\
Participate in groups & 1.87 & 0.30 & 1 & 2.18 & 0 & 10 \\
Use resources & 1.87 & 0.19 & 2 & 1.37 & 0 & 8 \\
Monitor progress & 0.26 & 0.11 & 0 & 0.76 & 0 & 0 \\
Seek support & 0.13 & 0.05 & 0 & 0.39 & 2 \\
\hline
\end{tabular}

Table 5 groups the average counts, and minimum and maximum counts for individual students, into the three focal 21st century learning themes we focus on in this paper.

Table 5: Descriptive statistics of opportunities for 21st century learning, as coded from user trace log data, grouped by theme.

\begin{tabular}{lccrrrr}
$\mathbf{2 1}^{\text {st }}$ Century learning themes & $\boldsymbol{M}$ & SE & Median & \multicolumn{1}{c}{ SD } & Min & Max \\
\hline Creative production & 77.41 & 3.29 & 74 & 23.97 & 36 & 135 \\
Social learning & 66.38 & 3.67 & 61 & 26.71 & 27 & 153 \\
Self-directed learning & 28.96 & 1.13 & 28 & 08.22 & 15 & 55 \\
\hline
\end{tabular}

These patterns follow what we know about the learning environment. Kellog focused on digital production, and youth were primarily prompted to use iRemix for creation and submission of digital artefacts. The educator described his students as more comfortable exploring as opposed to engaging in direct critique or interaction, and exploring the work of others was the next most common activity on the system. While students were not prompted to monitor their own progress or use the system for selfdirected inquiry, they were encouraged to post comments and develop their own profile page; both of these activities were required at least once. These average trends of more and less frequent types of activities follow the educator-driven aspect of the formal school classroom, but there was a lot of variability across the individual students. The histograms in Figure 6 show the distribution for each learning opportunity theme (note that the $x$-axis gradients are different for self-directed le arning as a result of lower counts for that type of activity). While the creative production counts were more or less distributed along a normal curve, the self-directed activity and social learning activity were skewed left, 
(2016). Revea ling opportunities for $21^{\text {st }}$ century learning: An approach to interpreting user trace log data. Journal of Learning Ana lytics, 3 (2), 37-87. http:// dx.doi.org/10.18608/jla.2016.32.4

indicating a higher level of variability on the higher end of the spectrum with a longer tail of highly active outliers.

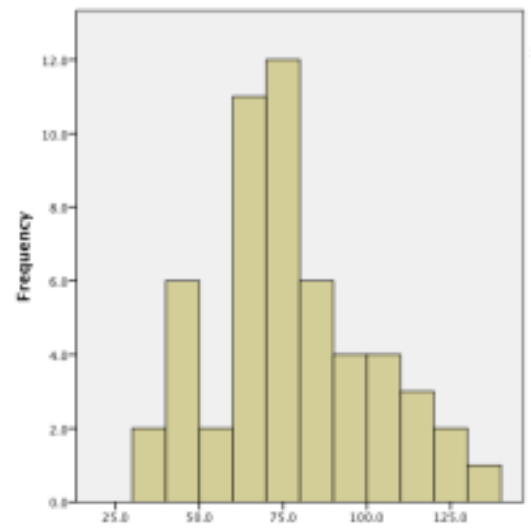

Creative production actions

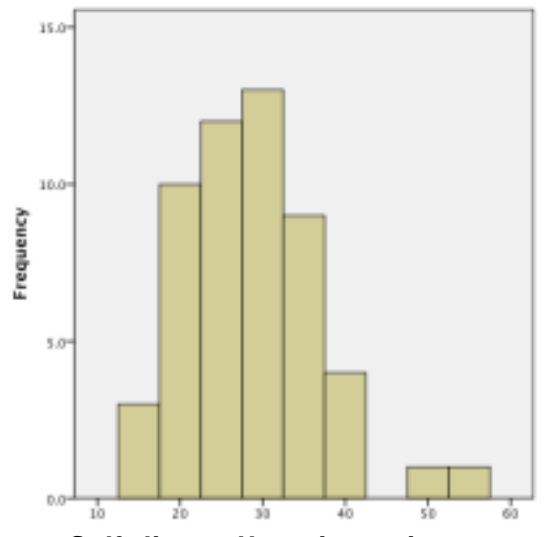

Self-directed learning actions

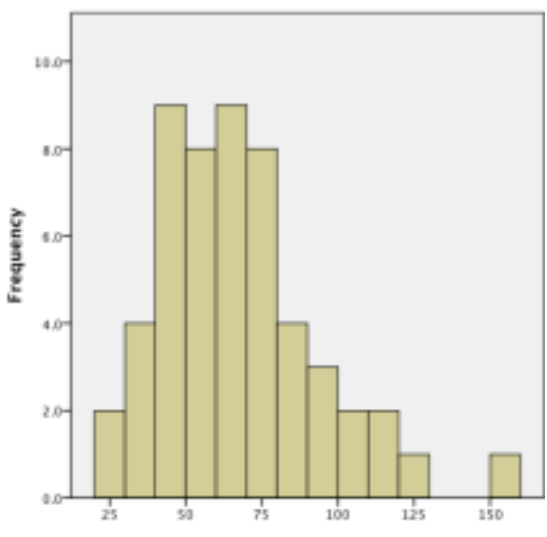

Social learning actions

Figure 6: Histograms of counts of clustered 21st century learning actions.

The number of overall counts of logged activities was correlated with the number of days students use $d$ the system, as was the count of creative production actions, $r(53)=0.75, p<.01$, and social learning actions, $r(53)=0.57, p<.01$, but there was no correlation between days on the system and the number of self-directed learning actions. Because self-directed activities such as using e mbe d ded resources and monitoring progress were possible but not explicitly prompted by the classroom educator, it makes sense that these counts were less likely to be a function of time on the system, and differences may suggest more independent student choice.

Given the variability of counts indicating opportunities for each 21st century learning the me, we were interested in finding out more about the students who evidenced more or fewer opportunities within each theme compared to their peers in the same learning environment. We used a median split of the counts (Table 4) to create higher and lower groups for each 21st century learning theme. Overall, $28.3 \%$ of students were in the lower group for all three themes, $28.3 \%$ were in the higher group for all three themes, and $44.4 \%$ were higher in some groups and lower in others. To explore theselogged user trace action counts as an indicator of potential opportunity for 21st century learning, in the next section we use these groups to look for correlations with survey self-report data related to these themes.

\subsection{Student Learners: Comparing Log Data Patterns and Self-Report Survey Data}

For each of the three 21st century learning themes - creative production, self-directed learning, and social learning - we first compare students in the higher and lower groups in terms of gender, home access to computing and technology, and regular technology-related online hobbies. A primary focus of DYN work is designing for equity, and we were interested to see if any of the dimensions shown to be predictors of and barriers to productive contribution and participation in some computing and online 
(2016). Revea ling opportunities for $21^{\text {st }}$ century learning: An approach to interpreting user trace log data. Journal of Learning Ana lytics, 3 (2), 37-87. http:// dx.doi.org/10.18608/jla.2016.32.4

activities (e.g., Hargittai \& Hinnant, 2008), were factors in counts of online activity that we think are generative for learning in iRemix. Then, we compare the students in the higher and lower groups along sets of survey items that have been used as metrics of student 21st century learning orientations with in similar themes (Barron, Gomez, Pinkard, \& Martin, 2014).

\subsubsection{Creative production groups}

The lower group had creative production opportunity counts ranging from 36 to 74 and accounted for $47.1 \%$ of learners $(n=25)$ while the higher group $(n=28)$ ranged in counts from 75 to 135 . These two groups looked similar in terms of their average proportions of user trace logs that accounted for opportunities of creative production (43.3\% and $46.2 \%$, respectively) and social learning activities ( $38 \%$ for both), but the lower creative production group had a significantly greater proportion of self-directed learning activities (19.1\% compared to $15.9 \%),(t(1,51)=2.52, p=.015)$. The students who were more engaged with production activities on the site spent less time focused on the aspects of the site where educators had set up resources for learning (i.e., progress along learning pathways, formal resources, and direct questions to the teacher). This may suggest that those students engaging in more creative production were using the site on their own time for more informal learning beyond what was required.

Gender, Access, and Digital Hobbies. The two groups did not differ in terms of gender $(61.5 \%$ of female $s$ and $44.4 \%$ of males were in the higher group), home access to computers and technology, and their regular online activities. However, although the groups reported spending similar amounts of time on social networking activities overall (surfing, posting, and commenting), those in the higher group were significantly less likely to report surfing ( $70.8 \%$ of the lower creative production group compared to $41.7 \%$ of the higher group, $2=4.15, p=.040)$. This finding potentially identifies those students in the higher creative production group as less likely to engage in passive exploration (i.e., surfing) in other networked environments, instead choosing to use their time to contribute.

Our definition of creative production involves developing an identity as a creator and understanding and utilizing appropriate media for production (Barron, Gomez, Pinkard, \& Martin, 2014). Here, we compare the higher and lower creative production groups on survey measures related to creative self-efficacy, confidence with technology activities, and interest in taking on a future role with technology (see Table 3).

Creativity and Technological Confidence. The sample overall had a very high rating agre e me $n$ t of the ir creativity ( $M=4.34, S D=0.62$, ranging from 3 to 5$)$, and there were no significant differences found between the higher and lower groups (see Table 5). The sample also had a high rating of overall confidence with technology ( $M=4.42, S D=0.64$, ranging from 2.5 to 5$)$, and for this measure there was an effect of creative production group, with the students in the higher group rating higher agreement with this construct. 
(2016). Revealing opportunities for $21^{\text {st }}$ century learning: An approach to interpreting user trace log data. Journal of Learning Ana lytics, 3 (2), 37-87. http:// dx.doi.org/10.18608/jla.2016.32.4

Table 5: Ratings of agreement of measures of creative self-efficacy and confidence with technology, by higher and lower creative production groups.

\begin{tabular}{llllll}
\hline Ratings of agreement & Group & $\boldsymbol{M}$ & $\boldsymbol{S E}$ & $\mathbf{F}$ & $\boldsymbol{p}$ \\
\hline Creative self-efficacy & Lower & 4.32 & 0.13 & 00.04 & NS \\
& Higher & 4.35 & 0.13 & & \\
Confidence with technology activities & Lower & 4.11 & 0.12 & 13.71 & .001 \\
& Higher & 4.72 & 0.11 & & \\
\hline
\end{tabular}

Whereas all students in Kellog's class were engaged in production through poetry, writing, and digital media, and we know the teacher fostered a creative expressive environment, those students contributing more online were submitting digital media artefacts, perhaps accounting for the higher technological confidence scores for those in the higher creative production group.

Potential Technology Careers. Those students doing more creative production activity on the system were significantly more likely than those in the lower creative production group to express a strong desire to enterfields of engineering, technologically enhanced design, and video production (see Table 6). Again, the digital creation identity of those in the creative producer group is apparent.

Table 6: Percentage of students who rated themselves extremely likely to go into different technological future jobs.

Creative production group

\begin{tabular}{lcclll}
\hline Possible technology-related jobs for the future & All & Lower & Higher & $\chi^{\mathbf{2}}$ & $\boldsymbol{p}$ \\
\hline Video editor or producer & $33.3 \%$ & $17.4 \%$ & $48.0 \%$ & 5.05 & .025 \\
Game designer & $18.8 \%$ & $13.0 \%$ & $24.0 \%$ & 0.94 & NS \\
Music producer or creator & $16.7 \%$ & $13.0 \%$ & $20.0 \%$ & 0.42 & NS \\
Graphic or web designer & $14.6 \%$ & $0.0 \%$ & $28.0 \%$ & 7.54 & .007 \\
Engineer or computer programmer & $12.5 \%$ & $0.0 \%$ & $24.0 \%$ & 6.31 & .014 \\
Network technician & $10.4 \%$ & $8.7 \%$ & $12.0 \%$ & 0.14 & NS \\
Computer teacher & $6.3 \%$ & $4.3 \%$ & $8.0 \%$ & 0.27 & NS \\
Writer or journalist & $6.3 \%$ & $4.3 \%$ & $8.0 \%$ & 0.27 & NS \\
\hline
\end{tabular}

In sum, those students choosing to do more activities related to creative production on the system, including posting and revising work, had higher confidence about their ability to work with technology and were more likely to think about a career in areas related to production with technology, including video editing, web and graphic design, and engineering. 
(2016). Revealing opportunities for $21^{\text {st }}$ century learning: An approach to interpreting user trace log data. Journal of Learning Ana lytics, 3 (2), 37-87. http:// dx.doi.org/10.18608/jla.2016.32.4

\subsubsection{Self-Directed Learning Groups}

The lower group accounted for $54.7 \%$ of learners $(n=29)$ and had self-directed learning opportunity counts that ranged from 15 to 28 , while the higher group $(n=24)$ ranged in counts from 29 to 55 . The groups were similar in terms of their average proportion logged as evidence of opportunities in the different areas of creative production ( $45.2 \%$ and $44.5 \%$, respectively), social learning ( $38.5 \%$ and $36.8 \%$ ), and self-directed learning opportunities (16.3\% and $18.8 \%$ ).

Gender, Access, and Digital Hobbies. There were no gender differences between groups, with $42 \%$ of females in the higher group and $48.1 \%$ of males. There were also no differences found between groups in terms of home access to computers and technology, nor for frequency of time spent on online hobbies, including social networking and gaming.

We define self-directed learning as seeking out information, being a lifelong learner, and making decisions (Barron, Gomez, Pinkard, \& Martin, 2014). As such, we compare the higher and lower selfdirected groups in terms of their Internet proficiency, given that it is becoming the primary means of consuming and searching for information, and their sustained experience with technology activities, suggesting troubleshooting and persistence (see Table 3).

Internet Proficiency. In this sample, the group with more evidence of self-directed learning activities on iRemix had significantly higher scores of Internet proficiency ( $M=50.94, S E=2.77)$ compared to those with fewer ( $M=43.35, \mathrm{SE}=2.30), \mathrm{F}(1,42)=4.46, \mathrm{p}=.041)$.

Sustained Fluency-Building Experiences. The breadth of fluency building experience looked similar for all students in the cohort ( $\mathrm{M}=6.62, \mathrm{SE}=0.19)$ and there were no differences between the higher and lower groups. However, students who exhi bited more self-directed learning activities had significantly higher depth scores (see Table 7), suggesting persistence in learning more and finding opportuniti es to do so, despite complex multi-faceted work. We also grouped the activities into three genres - publication (publication, website, podcast), expressive (art, music, video), and computational (game design, robotics, programming) - to see which genres of production students repeatedly engaged in. This genre classification system is only one way to group the activities, and most span multiple categories, but it has been used in previous work as a way to look at patterns of participation (Barron \& Martin, 2016). Students in the higher self-directed learning group had higher scores in each mode of technological production, suggesting both exploration and depth of involvement. 
(2016). Revealing opportunities for $21^{\text {st }}$ century learning: An approach to interpreting user trace log data. Journal of Learning Ana lytics, 3 (2), 37-87. http:// dx.doi.org/10.18608/jla.2016.32.4

Table 7: Sustained experience with creative production activities of students with lower or higher evidence of self-directed learning.

\begin{tabular}{cccccc}
\hline & $\begin{array}{c}\text { Self-directed } \\
\text { learning group }\end{array}$ & $\boldsymbol{M}$ & SE & $\mathbf{F}$ & $\boldsymbol{p}$ \\
\hline Breadth score & Lower & 6.63 & 0.25 & 00.01 & NS \\
& Higher & 6.60 & 0.29 & & \\
Depth score & Lower & 1.89 & 0.31 & 17.96 & .000 \\
& Higher & 3.86 & 0.35 & & \\
Computational depth & Lower & 0.30 & 0.12 & 7.59 & .008 \\
& Higher & 0.81 & 0.14 & & \\
Publication depth & Lower & 0.19 & 0.11 & 5.33 & .026 \\
& Higher & 0.57 & 0.13 & & \\
Expressive depth & Lower & 1.41 & 0.18 & 13.87 & .000 \\
& Higher & 2.48 & 0.21 & & \\
\hline
\end{tabular}

In summary, those students who exhibited more self-directed learning activity on iRemix, incl uding using resources and materials, looking for unassigned activities, and monitoring progress, had higher Internet proficiency proxy scores and were more likely to have sustained experience in each type of computing activity we asked about, including expressive, computational, and publication. These students were savvy navigators of the dense and complex web of information, perhaps finding information and opportunities for learning more. Their depth of experience with multimedia fluency building activities suggests persistence with particular genres of production beyond playing around (Ito et al., 2009). Activities that can encourage development of computational fluencies have increasingly been called out as especially rare but important for young people (Wing, 2006, 2011; Barron \& Martin, 2016). This is an especially interesting group to look at in the context of Mr. Kellog's classes, as we know that actions mapped to self-directed learning opportunities in our framework were not guided by the instructor.

\subsubsection{Social Learning Groups}

The lower activity group accounted for $52.8 \%$ of learners $(n=28)$ and had social learning opportunity counts that ranged from 27 to 61 , while the higher group $(n=25)$ ranged in counts from 62 to 153 . The average proportion of activities within themes was significantly different between the two groups for each of the three 21st century learning themes. On average, the higher social learning group evidence $d$ a higher proportion of actions logged overall that were classified as social learning opportunities $(t(51)=-$ 4.82, $\mathrm{p}<.001)$, and lower proportions of actions classified as opportunities for creative production $(t(51)=2.12, p=.039)$ and self-directed learning $(t(51)=3.24, p=.002)$. On average, the higher group logged actions that classified as $43.1 \%$ creative production, $41.6 \%$ social learning, and $15.3 \%$ self-directed learning, compared with the lower group $46.5 \%, 34.2 \%$, and $19.3 \%$, respectively. This higher gro up may reflect student choice to interact with others both publically (e.g., commenting on work) and privately 
(2016). Revea ling opportunities for $21^{\text {st }}$ century learning: An approach to interpreting user trace log data. Journal of Learning Ana lytics, 3 (2), 37-87. http:// dx.doi.org/10.18608/jla.2016.32.4

(e.g., looking at the work of others), as opposed to those that only carried out actions in relation to peers or the teacher that were part of required assignments on the system.

Gender, Access, and Digital Hobbies. While there were no significant differences found between higher and lower social learning groups in terms of home access to computers and technology, or in terms of frequency of digital hobbies, there was a significant gender difference (a $2=6.80, p=.009$ ); the higher group was comprised of $68.0 \%$ female and $32.0 \%$ male, while the lower group was $32.1 \%$ female and $67.9 \%$ male. Sixty-five percent of females were in the higher group compared with $29.6 \%$ of males. Interestingly, there were no gender differences in terms of student self-reports of use of online social network sites.

We define social learning activities as being those related to communicating and collaborating around work and ideas, including teaching and learning from others and being open to new ideas and perspectives (Barron, Gomez, Pinkard, \& Martin, 2014). Below, we compare the higher and lower social learning groups in terms of their reports of their technology learning network, their use of online communities for learning, and their perceptions of getting new perspectives from being online (see Table 3).

Face-to-Face Learning Networks. Both groups were teaching multiple types of people in their ne twork about technology (higher group $\mathrm{M}=3.20, \mathrm{SE}=0.48$; lower group $\mathrm{M}=3.18, \mathrm{SE}=0.44$ ). However, there was a main effect of group for the types of people from whom they learned $(F(1,46)=5.33, p=.026)$. Counter intuitively, those youth in the higher social learning group reported a significantly smaller ne twork of people from whom they learned $(M=6.27, S E=0.53)$ compared to the lower group $(M=7.92, S E=0.48)$.

Learning Online. Over a third of students in both groups reported learning a lot from online communities ( $40.7 \%$ of the lower group and $45.5 \%$ of the higher), and there was no difference between groups. On average, students agreed that they got new perspectives on societal issues using the Internet $(M=3.92$, $\mathrm{SE}=0.17)$, but students in the higher social learning activity group agreed more $(\mathrm{M}=4.36, \mathrm{SE}=0.25)$ than those in the lowergroup ( $M=3.48, S E=0.24),(F(1,45)=6.49, p=.014)$.

In summary, the students who were higher on social learning reported learning from fewer people about computers and technology in theirface-to-face world. They were more likely to agree that they had gotten new perspectives on societal issues because of their use of the Internet. The two groups looked similar to each other in terms of who they taught and how they used online communities for learning. Kellog's class was engaging as a group in digital media skills, and it is no surprise that all of the students report teaching their face-to-face network, including parents, grandparents, peers, and siblings. Although surprising that the higher social learning group report learning from fewer types of people, we wonder if those youth were not connected to expertise in their face-to-face learning network or if they may be more technologically savvy and therefore not seeking out help from others in the content area of computers and technology. 
(2016). Revea ling opportunities for $21^{\text {st }}$ century learning: An approach to interpreting user trace log data. Journal of Learning Ana lytics, 3 (2), 37-87. http:// dx.doi.org/10.18608/jla.2016.32.4

\subsubsection{Survey items across groups}

As a way of adjusting for the possibility that higher and lower counts of activity overall account for differences in the survey data, we compared higher and lower groups for other themes for all survey items. Three items - technological confidence, Internet proficiency, and depth of experience with technological fluency-building activities - revealed significant differences betwe en higher and lower groups outside of the targeted 21st century theme.

Like the creative production groups, the higher self-directed learning group had higher technological confidence $(M=4.69, S E=0.09)$ than the lower group $(M=4.22, S E=0.14), F(1,46)=7.05, p=.011$. They also were more likely to see a future in game design (38.1\% compared to $3.7 \%$ of the lower group, $2=9.17$, $p=.003$ ) and video production (57.1\% compared to $14.8 \%$ of the lower group, a $2=9.52, p=.003$ ). We know that the learning goals and production work assigned to these students were focused on digital media and technology activities, so it is not surprising that those students who logged more opportunities for self-directed learning in the iRemix system considered themselves to be technologically confident and interested in digital and computational pursuits.

Like the self-directed learning groups, the higher social learning group had significantly higher scores of Internet proficiency $(\mathrm{M}=50.90, \mathrm{SE}=2.60)$ compared to those in the lower group $(\mathrm{M}=42.75, \mathrm{SE}=2.37)$, $(F(1,42)=5.36, p=.026)$, suggesting that those students who engaged in more social interactions online were developing more Internet savvy skills in general as they navigated onlinespaces and networked communities.

Perhaps most interesting, the higher groups of each 21st century learning theme - creative production, self-directed learning, and social learning - had a higher depth of experience with fluency building activities than their lower group counterparts. While the self-directed learning groups differed across all genres of production, here we found that the higher creative production group had a higher depth of experience than the lower $(M=3.32, S E=0.36 ; M=2.13, S E=0.37 ; F(1,46)=5.34, p=.025)$ and for expressive activities $(M=2.36, S E=0.19 ; M=1.35, S E=0.20 ; F(1,46)=13.14, p=.001)$, and the higher social learning group had higher depth of experience than the lower $(M=3.64, S E=0.36 ; M=2.00, S E=0.33$; $F(1,46)=11.20, p=.002)$ and for both expressive $(M=2.36, S E=0.21 ; M=1.46, S E=0.20 ; F(1,46)=9.79$, $p=.003)$ and publication activities $(M=0.55, S E=0.12 ; M=0.19, S E=0.11 ; F(1,46)=13.14, p=.041)$. This suggests a portrait of all of Kellog's students who were active online as deeply engaged in sustained media production, with those in the higher creative production group focusing on expressive media, those in the higher social learning group focusing on expressive media and publication as they share their ideas with others, and the self-directed group engaged in sustained participation across ge nres of production, including computational.

Importantly and obviously, there are serious limitations to this approach and interpretation of re sults. Because this data is correlational we do not attempt to make causal claims nor do we claim that actions in the system are equated with an instance of learning, but instead report on relationships between 
(2016). Revealing opportunities for $21^{\text {st }}$ century learning: An approach to interpreting user trace log data. Journal of Learning Ana lytics, 3 (2), 37-87. http:// dx.doi.org/10.18608/jla.2016.32.4

experiences of opportunity logged in the system and self-report of experiences and perceptions. We do not know if the students who are coming in with more evidence of 21st century learning are using the site in different ways or vice versa, nor can we say that a click on the system that logs an activity is equal to a learning activity. Rather we look at these logged activities as opportunities for learning. This research was emergent, and we used data collected over a six month design-research effort, incl uding surveys and interviews, to better understand the iRemix log data that was collected. Also while we report statistical significance and use the accepted level of less than 5\% (.05) to determine that differences are not happening by chance, we recognize that for each of the findings there is the potential for a type I error, meaning a null hypothesis is true.

\subsection{Focal Learner Cases: Amaya and Sterling}

To better understand the results in the online log data and the triangulation of the log patterns with survey data, we developed qualitative cases of individual learners. This allowed us to learn about the backgrounds they brought to the experience of using iRemix in the classroom and more about their own intentions of use. In the sections below, we share narrative stories of two of Kellog's students: Amaya, who scored in the higher group for all three types of 21st century learning activity on iRemix, and Sterling, who scored in the lower group for all three (see Figure 7). Amaya had a creative production opportunities count of 111 (89th percentile), a self-directed learning opportunities count of 35 (79th percentile), and a social learning opportunities count of 74 (69th percentile). Sterling had a creative production opportunities count of 40 (6th percentile), a self-directed learning opportunities count of 22 (19th percentile), and a social learning opportunities count of 61 (50th percentile).

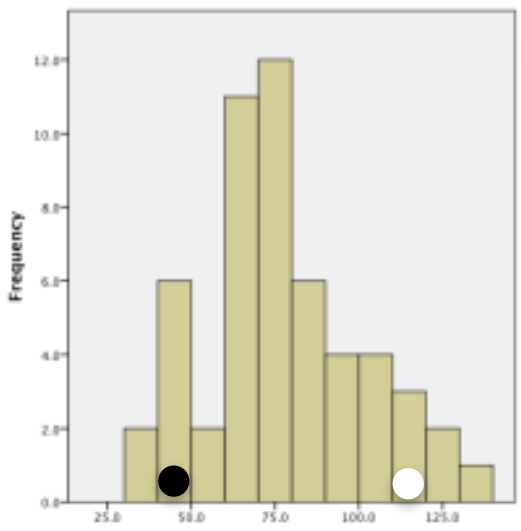

Creative production actions

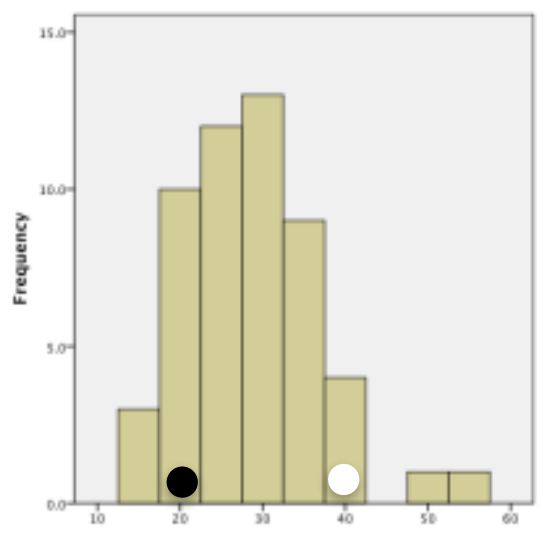

Self-directed learning actions

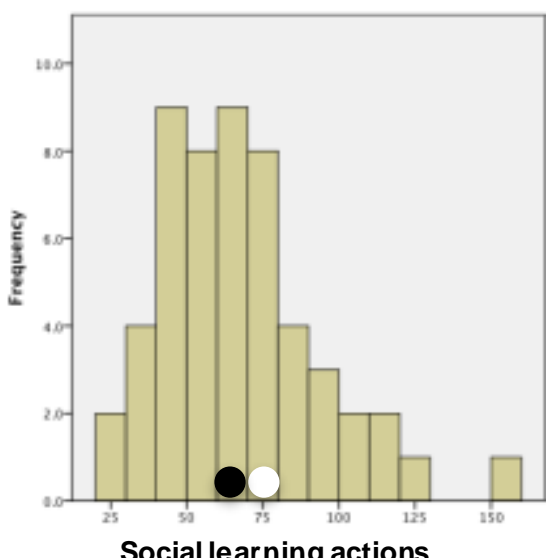

Social learning actions

Figure 7: Histograms of 21st century activity counts with focal case learners located, a light circular marker for Amaya and a dark circular marker for Sterling. 
(2016). Revea ling opportunities for $21^{\text {st }}$ century learning: An approach to interpreting user trace log data. Journal of Learning Ana lytics, 3 (2), 37-87. http:// dx.doi.org/10.18608/jla.2016.32.4

\subsubsection{Amaya: embracing storytelling through digital media and making plans for learning more}

I usually like to think outside the box. So I like to be unique with my [digital media] stuff, like not the same as everyone else's, like at least one thing that stands out.

Amaya was a 12-year-old girl who described herself as Latina. She lived near the school with her parents and her younger brother. She was involved in a number of regular extracu ricular activities, including cheerleading, karate, piano, and guitar lessons. Amaya was highly engaged in narrative stories of any kind, and enjoyed watching movies and reading books in her free time. She had personal access to technology and the Internet at home, including a wireless connection and her own MacBook, and was very interested in technology. On her iRemix profile, she declared her affinity with computers, "When it comes to computers I go crazy! I could spent hours on them, but then have no ti me to read!" Her entire family regularly used computers for basic Internet searches and entertainment, and her mother, a daycare teacher, used it for work to create simple lesson plans. On her own time, Amaya frequently went online to search for information about her hobbies, use social networking sites, and less frequently played adventure games. She specifically wanted to learn more about "how to make websites, and more video editing."

Her interests and pursuits outside of iRemix very much align with her counts of online learning opportunities that place her in the higher groups in terms of all three dispositions the DYN program is interested in fostering - creative production, self-directed learning, and social learning.

Creative Production. Amaya logged one of the highest counts of potential creative production opportunities in iRemix in her grade. Offline, she similarly identified very much as a creative producer, both in and out of school. She was proud of the work she created and found ways to blend he rgrowing technological knowledge with her personal interests. She described using tools on her Mac at home to create and edit videos and images, including using Pixlr, a tool learned in Kellog's class, to e dit a photo her father had taken of her doing karate, to make it more dramatic and "really cool." In school, her interest in narratives in different formats immediately tied into Kellog's class focus on multiple modes of expression.

Her favourite school project was a book report in Kellog's class where students were given the option to create an imagined video movie trailer for the story. "I spent a lot of time with it," she related, "and it was more unique than the rest of them because it was in first person view and everyone else did it in third person view. I showed it to my parents. They thought it was cool." The book chosen by Amaya was Cinder, a popular young adult novel retelling the Cinderella fairy-tale as dystopic science fiction (see Figure 8). Amaya blended film footage, still photos, sound effects, layered musical soundtracks, and captions with subtle transitions into a two-and-a-half minute movie that conveys a moving portrait of futuristic and social hardship from the perspective of the protagonist. Amaya played on traditional movie trailers (using opening shots from Time Warner), the book's genre bending (the traditional "Once upon a time" shot is followed by the sound of a scratching record and the words, "I wish I could tell you 
(2016). Revea ling opportunities for $21^{\text {st }}$ century learning: An approach to interpreting user trace log data. Journal of Learning Ana lytics, 3 (2), 37-87. http:// dx.doi.org/10.18608/jla.2016.32.4

that story, but it's not mine"), and uses elements of popular Sci-Fi and horror movies (escalating music, a blank screen and pause in audio, and a disturbing phone-call conveyed in words and images).
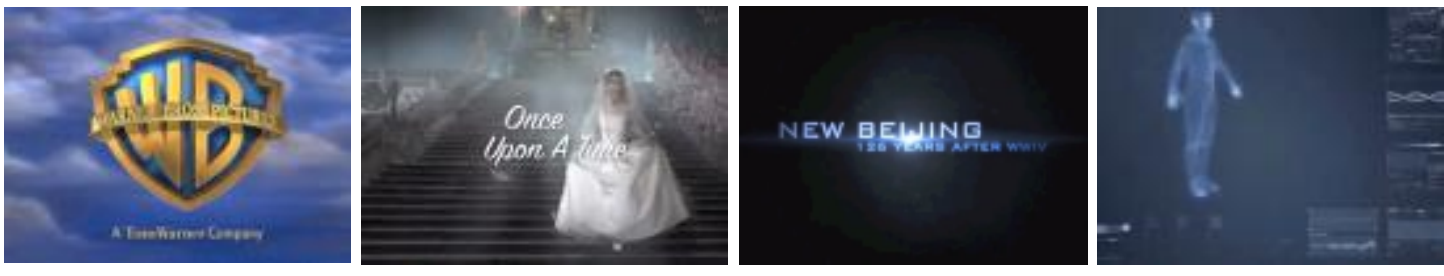

Figure 8: Stills from Amaya's book review trailer digital movie.

Amaya described her use of iRemix as a combination of posting assigned work and sharing her own creations and other found media. During the six months of log data collection, Amaya posted 14 blog posts, 13 videos, 8 images, and 2 audio files to the site, and had two notes in her notebook. Like her video book report submission, many of her posts were related to contemporary young adult fiction, as when she shares her perspectives on books like The Fault in Our Stars and The Hunger Games.

Amaya's role as a creative producer of digital media was re cognized through her work in Kellog's class. Kellog reflected that Amaya felt more comfortable sharing hertalents and ideas through movies, "She's really quiet, but she's super creative with her iMovies and just really outgoing." Whe n asked which of their peers was good with computers, Amaya was the seventh most nominated in her grade (13\% of students selected her). Positive comments on her work were frequently posted by her peers in iRemix, such as this one on her book movie trailer: "Amaya, this is soooo ooooo000000 cool I love the end!"

Self-Directed Learning. Aligning with her high count of self-directed learning opportunities in relation to her classmates, Amaya revealed a number of ways in which she regularly navigated her own learning as she connected to networked tools and information online. For example, al though she was unsure about the availability of video editing classes in high school, she planned to "continue to teach myself. I am mostly using the Internet," and talked specifically about following individuals who post tuto rials about video editing on sites like YouTube. She also engaged in online research to troubleshoot problems that came up when she worked through digital media projects or other homework, and used Kahn Aca demy on her own time to play educational math games. This self-direction is evident on her i Remix portfolio, which documents final versions of all assigned work and completion on all assigned learning path ways despite the fact that this level of closure was not necessarily required by Mr. Kellog for the digital media projects in his class. Amaya recognized the iRemix portfolio space as a way to keep track of work (students often used different laptops from day to day) and to showcase it outside of class. She reported, "iRemix is an easy way to know where you put a certain thing," and talked about using the system to show her media submissions to friends and family at home. Amaya logged onto iRemix outside of class time and described posts from home to "finish something up." She also planned to use it in the upcoming summer "to keep my brain fresh ... to get extra practice." She wanted more learning pathways tied to her specific interests, specifically covering more advanced video editing. 
(2016). Revea ling opportunities for $21^{\text {st }}$ century learning: An approach to interpreting user trace log data. Journal of Learning Ana lytics, 3 (2), 37-87. http:// dx.doi.org/10.18608/jla.2016.32.4

Social Learning. Although Amaya was both teaching and learning from others about computers and technology at home and at school, the social dimension was secondary to her independent work, and when she was social online it was often specifically tied to media and production. This aligns with her count of social learning opportunities online, where Amaya positioned her closer to the middle in relation to her peers, although she still remained in the higher group.

Amaya shared her knowledge with her mother, including helping her to use Google drive to create graphs, and at school $18 \%$ of her grade peers selected her as someone who they learn from. On iRemix, she engaged in the community aspect of the system by creating and joining iRemix groups tied to her interests in movies and popular novels. She enjoyed sometimes commenting on herfriends' work and took pride when she received comments on her own work, "It makes me happy that they took the time out of their day to look at my work. Yeah because they're like, 'This is cool, no one else posted this, let's check this out'." Her main social learning activity was to look at the work of others on iRemix, and she talked about learning from observation, "I like to see other people's creations, like I might get inspired and I have a couple of times by other people." Amaya's comments to others on the system were specifically about elements of their work, "I like how the music matched the tone of your poe m! Even though it was sad, I really liked it."

\subsubsection{Sterling: focusing on the performing arts and figuring out how to support it with production} I love performing ... A lot of people think I'd be good on Broadway and stuff.

Sterling was a twelve-year-old African American male actively involved with the performing arts, who described himself as an actor, singer, and dancer. He lived with his parents, two older brothers, and two older sisters. He participated in an afterschool choir program at a city high school but attended infrequently because it was difficult to find transportation consistently. Although he received good grades in school, he described himself as a "slow reader." He had his own computer at home, and the family had another computer, a tablet, and an Internet connection that Sterling described as slow. He regularly used the computer to play games, listen to music, and engage in social media sites, including Twitter and Facebook, at the library after school or at home after he finished homework.

His interests and pursuits outside of iRemix somewhat align with counts of online learning opportunities that place him in the lower of each of the creative production, self-directed learning, and social learning groups, but his qualitative case portrait helps to point out important nuances to supplement the story told by the log data.

Creative Production. Despite the fact that he was considered tech savvy at home, he did not define himself as a creative producer nor was that how he was perceived at school. When describing his iRemix profile page, he explained his focus on exercising creativity and expression through performance, "[In 'About Me'] I wrote 'Next on stage, he is very talented! He is such an amazing singer!' This is stuff that I want to do when I grow, like be a singer or whatever. This is how I wanted to express myself." Although 
(2016). Revea ling opportunities for $21^{\text {st }}$ century learning: An approach to interpreting user trace log data. Journal of Learning Ana lytics, 3 (2), 37-87. http:// dx.doi.org/10.18608/jla.2016.32.4

he saw the potential for iRemix as an outlet for performance, specific activities to do so we re not clear to him and they were not part of any of the existing learning pathways on the system, "If you are doing something like music-related then yeah. It depends on what subject and what you are doing in what subject."

The lack of obvious connections with his out-of-school interests resulted in iRemix being primarily a place for teacher-initiated assignments for Sterling. During our study, he posted 3 images, 2 sounds, 3 videos, 3 blog-posts, and 3 notebook entries; all required assignments. None of his peers identified him as someone who was knowledgeable about computers nor as someone they learned from. In te rms of his own perception of himself as a creative producer and public recognition in this area at school, Sterling's low creative production count is in alignment. At home, however, he dabbled in his own movie making. He transferred what he learned in iMovie on the school MacBooks in Kellog's class to his Dell computer, "It has these apps where you can make your own movie, but it's not called, like on Apple computer, iMovie, it's just called My Movie and Movie Creator, and it's sorta like iMovie, but the y have more effects and more stuff that you can put on there." He also had i deas for how to support his passion for the performing arts through digital production, such as making music videos of his performances or creating songs on digital audio editing programs, but felt he did not yet have these skills to do this and did not see these activities as tied to his work in Mr. Kellog's class or on iRemix.

Self-Directed Learning. Aligning with his lower self-directed learning opportunity scores on iRemix, Sterling did not pursue these digital production learning goals on his own and was sometimes frustrated when working independently. Sterling used the Internet to seek out potential future learning opportunities related to his interests, such as searching for potential performing arts high schools and colleges, but was not able to articulate a plan for his more immediate and direct desire to learn to create websites and produce quality audio and video pieces. He also described feeling stressed when he faced technical issues while working with technology, "Sometimes it gets difficult. ... Sometimes the computers have its own mind. It takes hard work. I also get stressed a lot because if what you se arched for is not on there, then you get frustrated and stuff." On iRemix, Sterling discussed sometimes going on outside of class time, but it was not tied to specific learning goals, "Once I was bored and it was a weekend and I didn't have nothing else to do so I went on to find extra credit work." Sterling did not complete any of the learning pathways that involved more than one activity step, suggesting that he had trouble persisting through multi-step projects: he completed one of the four Welcome to iRemix challenges, and two of the four RACE challenges.

Social Learning. While in the lower group, Sterling's count of opportunities for social lea rning on i Re mix was close to Amaya's and close to the middle in comparison to his classmates. Sterling was a very social person who enjoyed the company of others and sought an audience. The social nature of iRemix was what most easily fit with Sterling's interests and intentions online. At home, when his family needed help with the computer, they would ask Sterling or his 15-year-old sister, and he taught his brothers how 
(2016). Revea ling opportunities for $21^{\text {st }}$ century learning: An approach to interpreting user trace log data. Journal of Learning Ana lytics, 3 (2), 37-87. http:// dx.doi.org/10.18608/jla.2016.32.4

to crop images and make presentations in PowerPoint. He became engaged in social media after hearing other students talk about theirfollowers, "I decided to do it, 'cause it was making me so competitive ... also not just for that, I just wanted really just wanted to socialize with my friends and family that was far away from me."

The best part of iRemix for Sterling was the opportunity to share his work and profile to connect with others. He frequently used iRemix to show his family the work he was doing in class. He once showed his mother a blog he wrote about a family vacation and was happy that she liked it and that "it brought her memories when she was reading it." He especially enjoyed receiving positive feedback on his posts, but not necessarily those that might lead to revisions, "[I] hope for good comments, less stuff [I] need to improve on." His comments on other people's work were al ways encouraging, "I love your eat he al thy song sis, KEEP IT UP!" Sterling, in fact, wished that iRemix social functionality was more person -toperson oriented instead of focusing on communication around submitted artefacts, "In other we bsites you can leave messages and have conversations but you can't have it there. You can leave comments and stuff, but if there is a comment box with just that person then it would much easier." He used the groups feature to connect with others more around his general interests than artefacts, including joining, becoming a coordinator of, and posting to a group called "Beyoncé Fans" with 13 members, and creating a group based on love of the colour purple, where he was the sole member. WhileSterling was not interacting around work and formal ideas as much as Amaya, these community and social opportunities logged around his personal interests identify the way he was able to engage with the learning community.

\subsubsection{Case learning comparison}

The 21st century log data framework positions Sterling and Amaya in terms of dimensions of creative production, self-directed learning, and social learning on iRemix. The way each student's log traces classified them make general sense: Amaya was a creative producer of digital media who both identified with and was recognized for this role, and regularly engaged in independent learning practices, and social interactions related to media production. Sterling was uncertain how to link digital production to his personal interests and found it difficult to navigate his own learning, although he coordinated a social sphere of learning partners for community interactions. While this was encouraging, the qualitative case portraits allowed us to see nuances both in what was happening and for what was possible. Both Sterling and Amaya considered themselves to be very creative, and this was an important part of their personal identity. Amaya was a creative producer of digital media such as video and artis tic projects, easily tying her personal interests in narratives to her production efforts, and this was evident on iRemix. Sterling's sense of his creativity was focused on performance and as of yet, he had not translated those pursuits into digital production. As such, Sterling did not have a strong re putation for creative production in the classroom nor did he log high counts of opportunities on iRemix, although his case reveals ample opportunity for encouraging a learner like him to do so. In terms of se If-directed learning, Amaya had clear learning goals and plans for achieving them, including a solid command of 
(2016). Revea ling opportunities for $21^{\text {st }}$ century learning: An approach to interpreting user trace log data. Journal of Learning Ana lytics, 3 (2), 37-87. http:// dx.doi.org/10.18608/jla.2016.32.4

utilizing networked resources on the Internet and a history of completing the work she began in i Re mix learning pathways, while Sterling did not see opportunities for learning on his own and sometimes became frustrated trying to do so. These representations correlate to the iRemix logs, where Amaya was very high compared to her classmates and Sterling was on the lower end. The social learning gro u $p$ was where these students look similar. Although Amaya was in the higher group and Sterling in the lower group, their actual counts were very close; both enjoyed the social learning dimension of the site. Amaya was more likely to discuss social learning activity as a means for learning more, whereas Sterl ing highly enjoyed the social aspect of this type of learning activity, which we know is still important for learning as he builds community online, with the potential for future recognition or al ignment a round interests or expertise. Although Amaya was recognized by classmates as having expertise in digital production through sharing her work and teaching others, aligning with her high counts on the public facing iRemix site, both used iRemix to showcase work at home with their parents, and both taught family members and were called upon for help with computers and technology at home.

\section{DISCUSSION}

In this paper, we present a multi-level approach to understand how log data might reveal patterns of activity that represent opportunities for creative production, self-directed learning, and social le arning. This study was motivated by the increasing presence of $\mathrm{K}-12$ online learning environments and conce rn about equitable access and generative participation for all youth. We posit that the data that can be collected from such systems offer enormous potential to understand how and when youth take up opportunities for 21st century learning practices and how best to support it. While our work is exploratory, in the following section, we highlight some of the interesting findings, implications, and opportunities for further study that have emerged in the course of this study.

\subsection{Interpretation of Logged Actions: Actor and Recipient}

To interpret the user traces, we looked at logged activities in terms of the actor and the recipient of each activity, attending to roles of self, peer, and educator, aligning with approaches defined in social learning analytics (Buckingham Shum \& Ferguson, 2012). We then organized a concept ual framework of logged actions building on prior DYN design-based research and theoretical constructs from recent work in the fields of learning sciences and human-computer interaction. Although this work is still in early stages, we found patterns of user trace data logs that triangulated with self-report measures of 21st century learning dispositions that DYN was designed to foster. Specifically, students with more creative production activity on iRemix were more likely to identify themselves as pursuing possible futures as engineers, computer-enabled designers, and video producers, suggesting personal identification as a technological creator. Those with more independent learning activity on iRemix had higher measures of sustained creative project experience across different genres of media, including computational activities such as programming and robotics, suggesting possible connections to persistence, use of personal and material resources, and troubleshooting. Those students who evidenced more social 
(2016). Revea ling opportunities for $21^{\text {st }}$ century learning: An approach to interpreting user trace log data. Journal of Learning Ana lytics, 3 (2), 37-87. http:// dx.doi.org/10.18608/jla.2016.32.4

learning activity on iRemix were more likely to agree that they got new perspectives on social issues through their use of the Internet, and reported learning from fewer people in the face-to-face contexts.

There were no differences of logged activities in the three 21st century learning themes we looked at in terms of student home access, which we use as a proxy for socio-economic status, indicating similar usage of iRemix by students from households with varying learning supports. Gender did not play a role in creative production or self-directed learning opportunities on iRemix, although girls engaged in more social learning opportunities logged on the system. Although the boy and girls in this study reported similar frequency of use on other social network sites, they were all under 13 years old, meaning that they were not technically allowed on public social media platforms as per COPPA standards - these girls perhaps had not yet begun to differentiate in more public social networks. National studies of te en use of technology platforms have found that girls dominate some social media platforms, especially those revolving around visual artefacts (Lenhart, 2015). Looking for ways to ensure that boys remain engaged in social learning activities around medi a artefacts in iRemix as they develop as young adults is an important outcome of these findings.

We believe that ways to look deeply at activities online that go beyond more traditional metrics of time on task and completion rates are critical to understan ding systems for different populations, and believe that the method of coupling action with the relationship between actor and recipient is an important contribution. Our next step is to carry out a systematic research intervention to validate our explorat ory conceptual coding frameworks using external measures of 21st century learning, such as existing verbal and performance-based measures of creativity (e.g., Silvia et al., 2008) and persistence (e.g., Shute \& Ventura, 2013).

\subsection{Interpretations of Logged Actions: Deep Knowledge of the Environment}

Each context of use determines success differently based on intentions, and the system should allow for multiple representations and visualizations of data to reflect different potential uses of the system, attending not only to more traditional metrics of time on task and completion rates, but also to practices that may be evidence of opportunities to develop important skills and dispositions that go across specific content areas and grade levels. Learning deeply about our focal learning environment, including the community and the teacher and his students, allowed us to further interpret the results that emerged in our coding of the logged user trace data. In other words, quantitative data begins to tell the story, but to design better environments and practices within those environments, especially in ways that can ensure that all youth have access to generative learning opportunities in online environments, we need other strategies to piece together a more complete picture of what is going on.

Although iRemix was designed with intentional support for student-driven activity, it purposefully includes learning management features for adults in the system, to guide use. In Kellog's classroom, his intentionality as a teacher and the climate of the learning environment influenced student use of the 
(2016). Revea ling opportunities for $21^{\text {st }}$ century learning: An approach to interpreting user trace log data. Journal of Learning Ana lytics, 3 (2), 37-87. http:// dx.doi.org/10.18608/jla.2016.32.4

site. The majority of logged activity was related to creative production, aligning with Kellog's strong focus on fluency and personal expression with digital media production. This was connected to his introduction to the system through DYN and the digital literacy initiative in his classroom during his first year of teaching. It was also connected to ideas about his student population, including wanting to increase their ability to express themselves in multiple modalities given their reluctance for sharing in person. For Kellog, successful use of the system was evidence of generative student creative production on the site, including assigned and voluntary posts and social interactions around those posts. Importantly, two key factors that made it possible for him to use this platform in a way he deemed successful were long-term regular use of the system with his students - allowing for the establishment of community norms and a growing body of submitted work and activity - and the support of his administration to implement an experimental system used for more free expression in a core subject classroom.

We are very interested in the way Kellog used informal exploration of digital media to intentionally encourage youth voice in his classroom, which has interesting implications for using an online platform to promote online contributions from under-represented populations. Studies have revealed that contributors of online content in general are a small subset of the population using technical systems, and that this subset is not representative of the larger population (e.g., Glott, Schmidt, \& Ghosh, 2010). As more people select online sources, including social networking sites, for social and political information, there are implications related to the critical need for equitable and balanced pers pectives on the Internet.

The importance of exposure to and experiences in participatory cultures and community for building skills, developing interests, and becoming creators and contributors is well documented (Hargittai \& Walejko, 2008; Ito et al., 2009; Jenkins et al., 2009). Log data showed many opportunities for creative production and social learning, but not as much for self-direction. Research in higher education has found that while some students are able to utilize social learning networks like iRemix to drive their own learning needs, importantly, not all students possess the knowledge management or self-regulatory skills to do so, and authors point out the need for scaffolded instructor use of system features (Dabbagh \& Kitsantas, 2012). Consistent with this, our study documented wide variability across individual you th learners on the system. Previous research has identified characteristics of lifelong learners as responsible for their learning process, able to span formal and informal, and heterogeneous in their approach to learning goals that they look for and achieve (Koper \& Tattersall, 2004).

We saw that while Amaya was a learner who regulated her activities, Sterling needed outsideguidance and was more likely to stay within the boundaries of what was asked of him by the teacher. The se case portraits enabled us to see nuances within general alignments and, as such, opportun ities for better design, practices, and teacher professional development to connect youth to more engagement in potential learning opportunities online. For Amaya, the content of the class using multiple media to 
(2016). Revea ling opportunities for $21^{\text {st }}$ century learning: An approach to interpreting user trace log data. Journal of Learning Ana lytics, 3 (2), 37-87. http:// dx.doi.org/10.18608/jla.2016.32.4

explore traditional literacies mapped onto her existing interests, and this led her to pursue more resources, look at the work of peers, and find opportunities to learn more. For Sterling, the conn ection between the course content and his personal interests and identity was not as obvious, but he was slowly finding ways to explore his own interests in iRemix through his profile page and by organizing special-interest communities, like his Beyoncé group. Opportunities to engage Sterling in media production around his performance artistry and creativity perhaps could become more possible for the teacher and peers to recognize as Sterling became more visible as a creative person with in the iRe mix site. Both case learners were interested in learning more digital production tools, including web and video development; opportunities for embedding or linking resources and visible pathways to support youth to go further in their learning outside of the boundaries of the classroom is something we are very interested in implementing.

\subsection{Translating Generative Learning Intentions}

Educators and administrators need shared language to better articulate how their learning goals map onto potential outcomes and practices within online social learning networks so they can fully use the system and support their learners in ways that they care about, and so that they can influence purchasing decisions at the school and district levels. In our study, Kellog embraced the use of iRemix for creative production, a practice he established during his first year of teaching. While iRemix included features for other types of learning opportunities that aligned with his ELA curriculum, such as discussion forums and debates, Kellog "stuck with what he knew." Although he spoke of consciously trying to support his students to take control of their own learning, system log data that we associated with self-directed learning opportunities on iRemixindicates that these features were almost never used in his classroom, such as monitoring progress, using embedded resources, and seeking help for assignments. For educators, there is a demand for professional development that not only helps them use technology, but also helps keep them "technologically agile" in a world of rapid technological change (Borgman et al., 2008; ACCI NSF, 2011). Recent reports on the use of online learning systems suggest that schools often do not realize the training, time, and effort necessary to establish new systems in the classroom (Watson, Murin, Vashaw, Gemin, \& Rapp, 2011). While ongoing useful professional development is critical, it cannot keep up with the rate at which new learning technologies and platforms are being introduced at district, school, and individual classroom levels. We posit that clearly articulating how features and corresponding student and e ducator use of those features map onto opportunities for learning may be one way to help teachers navigate environments for their classroom in more intentional ways. Organizing our features and interpretations of logged activity traces into themes aligned with DYN goals and national efforts to define 21st century learning allowed us to talk to educators about both the site features and capabilities, and potential opportunities for youth related to those aspects of the system. We believe that continuing to develop and use language for looking at evidence of 21st century learning online is critical for translating what we see. Teachers need to know how to translate intentions that may be more abstract, such as Mr. Kellog wanting to nurture 
(2016). Revea ling opportunities for $21^{\text {st }}$ century learning: An approach to interpreting user trace log data. Journal of Learning Ana lytics, 3 (2), 37-87. http:// dx.doi.org/10.18608/jla.2016.32.4

self-directed learners, into practical learning designs and online tasks, selecting appropriate tools and features. We see this as an important step in supporting practitioners to use platforms for more than just traditional distribution of assignments and quizzes and collection of homework, and moving forward to help design better online learning environments across different content, ages, and communities. The ability to log activities that go beyond time-on-task and submissions make these more abstract types of learning actions and opportunities more assessable for teachers in both formative and summative ways.

\subsection{Using a Bottom-Up Approach}

This paper presents an exploration of a socio-technical system, specifically looking for interesting patterns in quantitative logged user traces and trying to understand the patterns more deeply through self-report data and qualitative cases. Although it is not the focus of this paper, this work is part of a larger three-year design-based research project (Collins, 1992; Brown, 1992; Hoadley, 2002) to understand learning environments in real-world contexts using a process of design, implementation, and iterative refinement.

The DYN organization is comprised of educators, learning scientists, and computer scientists. To make sense of the data generated from logged activity over three years - including engaging in powerful learning analytics and educational data mining to look at clusters of activities, change over time, and profiles of users - we realized we first needed a crystal clear understanding of the iRemix system that had emerged over the course of ten years, to the detail of each minute of activity that was logged. To engage in cycles of design, implementation, and iterative refinement, and utilize these new processes of data analytics to reflect learning, we needed a model that 1) our entire team felt was authe $n$ tic to the DYN program and design intentions, 2) reflected the way the system was used in different contexts, and 3) practitioners could also understand. The methodology and framework of 21st century learning opportunities takes into account the system features, the data it collects, the actors in the system, and the objects they interact around. As such, we developed these higher order constructs related to opportunities on the site for creative production, self-directed learning, and social learning, grounded in lower level activity logs. This allows us to attend to practices of use (e.g., Which features are being us ed and which are not? What opportunities for learning are not being taken up by educators or youth on the system? How can we better support youth?), and to make sure we understand individual actions that are logged on the system, and that we are collecting the right actions with enough meta-data to make interesting claims about learning. Without this deep understanding, alignment, and agreement, the data generated from more top-down approaches did not make sense to the team of practitioners and learning designers, and did not, therefore, result in direct opportunities for action, inclu ding platform redesign and revisions to professional development to promote teacher practices. 
(2016). Revea ling opportunities for $21^{\text {st }}$ century learning: An approach to interpreting user trace log data. Journal of Learning Ana lytics, 3 (2), 37-87. http:// dx.doi.org/10.18608/jla.2016.32.4

\section{$7 \quad$ CONCLUSION AND FUTURE WORK}

The more we can define, cluster, and compare different types of environments, the easier it will be to conduct meaningful research, interpret results, and build on the research efforts of others. The potential for mining online data and applying learning analytics is exciting, but we need to be clear about different type of online environments, their various features, their learning goals, and potential outcomes to be able to design robust research efforts and analyze and begin to compare results. We present our methodology of automated coding of 21st century learning opportunities as part of a larger initiative to understand and discuss the rapidly growing number of online learning environments, and we believe it to be both beneficial and necessary for designers, practitioners, and researchers in and of such environments.

Our coding methodology is intended to illuminate the kinds of moves youth made online including youth-to-system interaction and youth-to-person interaction using automated coding of user trace data logs, with specific attention to relationship types of log action, actor, and recipient. Building fro $m$ the foundational learning ideas that support DYN design and programming, we developed a coding framework to look at opportunities for 21st century learning opportunities on iRemix within the mes of creative production, self-directed learning, and social learning. We intend to use this framework to look for changes in activity across time, and to develop visualizations to use with practition ers in ways that allow them to compare their learning goals with online activity, and see opportunities for changes in classroom practice and use of tools to promote different types of outcomes. We are also using this methodology to look at the system use in different environments with unique learning goals and populations, to find out more about how different practices determine student activity over time and what success looks like across contexts. In this paper, we have documented how we explore the authenticity of our logged data through student self-report survey data and qualitative case studies of individuals in the learning environment. We plan next to engage in empirical work to see if logged opportunities for 21st century learning correlate with validated external measures of 21st century skills.

Although iRemix does not adhere to current learning technologies' la nguage standards, the user trace coding methodology shared in this paper may be of interest to the learning analytics community and has the potential to be adapted for use with data from other platforms. For educators and professional development leaders, this work may also advance ways to articulate and share learning goals, opportunities, and patterns of use of online environments related to 21st century learning, aiding discussion and understanding of the complexities of educator roles and student behavi ours online. Above all, our work is an exploration of and ongoing design effort to create online learning environments as spaces that can provide youth with digital learning resources and a knowledgeable social network to support learning and development. 
(2016). Revea ling opportunities for $21^{\text {st }}$ century learning: An approach to interpreting user trace log data. Journal of Learning Ana lytics, 3 (2), 37-87. http:// dx.doi.org/10.18608/jla.2016.32.4

\section{ACKNOWLEDGEMENTS}

This material is based on work supported by the National Science Foundation Cyberlearning and Future of Learning Technologies grant (DIP \#1325004). Any opinions, findings, and conclusions or recommendations expressed in this material are those of the author(s) and do not necessarily reflect the views of the National Science Foundation. We acknowledge the entire staff of the Digital Youth Network, especially the iRemix development team of Akili Lee, Tre Everette, and Mark Ellul, and research assistants Jim Sandherr and Elaina Boytor. We are especially grateful to the middle school teachers, students, and administrators who contributed their time and invaluable pers pectives to this work.

\section{REFERENCES}

Allen, I. E., \& Seaman, J. (2008). Staying the course: Online education in the US. Needham, MA: Sloan Consortium. Retrieved from http://www.onlinelearningsurvey.com/reports/staying-thecourse.pdf

Ahn, J. (2013). What can we learn from Facebook activity? Using social learning analytics to observe new media literacy skills. Proceedings of the $3^{\text {rd }}$ International Conference on Learning Analytics and Knowledge (LAK'13), 135-144. http://dx.doi.org/10.1145/2460296.2460323

Aspen Institute Task Force on Learning and the Internet. (2014). Learner at the center of a networked world. Washington, DC: The Aspen Institute. Retrieved from http://csreports.aspeninstitute.org/documents/AspenReportFinalPagesRev.pdf

Advisory Committee for Cyberinfrastructure of the National Science Foundation (ACCI NSF) (2011). Task force on data and visualization (Final Report). Washington, DC: National Science Foundation. Retrieved from https://www.nsf.gov/cise/aci/taskforces/TaskForceReport Data.pdf

Bacow, L. S., Bowen, W. G., Guthrie, K. M., Lack, K. A., \& Long, M. P. (2012). Barriers to adoption of online learning systems in US higher education. New York: Ithaka S+R.

Barron, B. (2004). Learning ecologies for technological fluency: Gender and experience differences.Journal of Educational Computing Research, 31(1), 1-36. http://dx.doi.org/10.2190/1N20-VV12-4RB5-33VA

Barron, B. (2006). Interest and self-sustained learning as catalysts of development: A learning ecologies perspective. Human Development, 49, 193-224. http://dx.doi.org/10.1159/000094368

Barron, B., Walter, S., Martin, C. K., \& Schatz, C. (2010). Predictors of creative computing participation and profiles of experience in two Silicon Valley middle schools. Computers and Education, 54(1), 178-189. http://dx.doi.org/10.1016/j.compedu.2009.07.017

Barron, B., \& Martin, C. K. (2016). Making matters: A framework for assessing digital media citizenship. In K. Peppler, Y. Kafai, \& E. Halverson (Eds.), Makeology (Vol2): Makers aslearners (pp. 45-72). New York: Routledge.

Barron, B., Gomez, K., Pinkard, N., \& Martin, C. K. (2014). The digital youth network: Cultivating digital media citizenship in urban communities. Cambridge, MA: MIT Press. 
(2016). Revea ling opportunities for $21^{\text {st }}$ century learning: An approach to interpreting user trace log data. Journal of Learning Ana lytics, 3 (2), 37-87. http:// dx.doi.org/10.18608/jla.2016.32.4

Bell, P., Lewenstein, B., Shouse, A.W., Feder, M. (Eds.). (2009). Learning science in informal environments: People, Places, and Pursuits. Washington, DC: National Academies Press.

Berlanga, A. J., Sloep, P., Brouns, F., Van Rosmalen, P., Bitter-Rijpkema, M., \& Koper, R. (2007). Functionality for learning networks: Lessons learned from social web applications. Proceedings of the ePortfolio 2007 Conference, 18-20 October 2007, Maastricht, the Netherlands (pp. 443453). Retrieved from http://www.eifeI.org/publications/eportfolio/proceedings2/ep2007/proceedings-pdf-doc/eportfolio-2007.pdf

Blikstein, P. (2013). Digital fabrication and "making" in education: The democratization of invention. In J. Walter-Herrmann \& C. Büching (Eds.), FabLabs: Of machines, makers and inventors (pp. 1-21). Bielefeld, GE: Transcript Publishers.

Borgman, C. L., Abelson, H., Dirks, L., Johnson, R., Koedinger, K. R., Linn, M. C., ... Szalay, A. (2008). Fostering learning in the networked world: The cyberlearning opportunity and challenge: $A 21^{\text {st }}$ century agenda for the national science foundation (Report of the NSF Task Force on Cyberlearning). Arlington, VA: NSF Task Force on Cyberlearning. Retrieved from http://www.nsf.gov/pubs/2008/nsf08204/nsf08204.pdf

boyd, d., \& Crawford, K. (2012). Critical questions for big data: Provocations for a cultural, technological, and scholarly phenomenon. Information, Communication \& Society, 15(5), 662-679. http://dx.doi.org/10.1080/1369118X.2012.678878

boyd, d., \& Ellison, N. (2007). Social network sites: Definition, history, and scholarship. Journal of Computer-Mediated Communication, 13(1). http://dx.doi.org/10.1111/i.1083-6101.2007.00393.x

Breslow, L., Pritchard, D. E., DeBoer, J., Stump, G. S., Ho, A. D., \& Seaton, D. T. (2013). Studying le arning in the worldwide classroom: Research into edX's first MOOC. Research \& Practice in Assessment, 8(1), 13-25. Retrieved from http://www.rpajournal.com/studying-learning-in-theworldwide-classroom-research-into-edxs-first-mooc/

Brown, A. L. (1992). Design experiments: Theoretical and methodological challenges in creating complex interventions in classroom settings. The Journal of the Learning Sciences, 2(2), 141-178.

Buckingham, D. (2007). Beyond technology: Children's learning in the age of digital culture. Malden, MA: Polity Press.

Buckingham Shum, S., \& Ferguson, R. (2012). Social learning analytics. Educational Technology \& Society, 15(3), 3-26.

Burch, P., \& Good, A. (2014). Equal scrutiny: Privatization and accountability in digital education. Cambridge, MA: Harvard Education Press.

Collins, A. (1992). Toward a design science of education. In E. Scanlon \& T. O’Shea (Eds.) , New directions in educational technology (pp. 15-22). Berlin, GE: Springer Verlag.

Dabbagh, N., \& Kitsantas, A. (2012). Personal learning environments, social media, and self-regulated learning: A natural formula for connecting formal and informal learning. Internet and Higher Education, 15, 3-8. http://dx.doi.org/10.1016/j.iheduc.2011.06.002 
(2016). Revea ling opportunities for $21^{\text {st }}$ century learning: An approach to interpreting user trace log data. Journal of Learning Ana lytics, 3 (2), 37-87. http:// dx.doi.org/10.18608/jla.2016.32.4

Gauntlett, D. (2012). Enabling and constraining creativity and collaboration: Some reflections after Adventure Rock. In S. Popple \& T. Thornham (Eds.), Content cultures: Transformations of user generated content in public service broadcasting (pp. 161-180). London: I. B. Tauris.

Girgensohn, A., \& Lee, A. (2002). Making Web sites be places for social interaction. Proceedings of the 2002 Conference on Computer Supported Collaborative Work (CSCW '02), 136-145. http://dx.doi.org/10.1145/587078.587098

Glott, R., Schmidt, P., \& Ghosh, R. (2010). Wikipedia survey: Overview of results. Maastricht, NE: UNUMERIT Collaborative Creativity Group. Retrieved from http://www.ris.org/uploadi/editor/1305050082Wikipedia_Overview_15March2010-FINAL.pdf

Greenhow, C., \& Robelia, B. (2009a). Old communication, new literacies: Social network sites as social learning resources. Journal of Computer-mediated Communication, 14, 1130-1161. http://dx.doi.org/10.1111/j.1083-6101.2009.01484.x

Greenhow, C., \& Robelia, B. (2009b). Informal learning and identity formation in online social networks. $\begin{array}{llll}\text { Learning, } \quad \text { Media } & \text { 119-140. }\end{array}$ http://dx.doi.org/10.1080/17439880902923580

Griffin, P., McGaw, B., \& Care, E. (2012). Assessment and teaching of $21^{\text {st }}$ century skills. Dordrecht, GE: Springer.

Guzzetti, B. J. (2006). Cybergirls: Negotiating social identities on cybersites. E-Learning, 3(2), 158-169. http://dx.doi.org/10.2304/elea.2006.3.2.158

Hargittai, E. (2005). Survey measures of Web-oriented digital literacy. Social Science Computer Review, 23(3), 371-379. http://dx.doi.org/10.1177/0894439305275911

Hargittai, E., \& Hsieh, Y. P. (2012). Succinct survey measures of Web-use skills. Social Science Computer Review, 30(1), 95-107. http://dx.doi.org/10.1177/0894439310397146

Hargittai, E., \& Hinnant, A. (2008). Digital inequality: Differences in young adults' use of the Internet. Communication Research, 35(5), 602-621. http://dx.doi.org/10.1177/0093650208321782

Hargittai, E., \& Walejko, G. (2008). The participation divide: Content creation and sharing in the digital age. Information, Communication \& Society, 11(2), 239-256. http://dx.doi.org/10.1080/13691180801946150

Hoadley, C. P. (2002). Creating context: Design-based research in creating and understanding CSCL. In G. Stahl (Ed.), Proceedings of the Conference on Computer Support for Collaborative Learning: Foundations for a CSCL Community (CSCL 2002), (pp.453-462). Boulder, Colorado:International Society of the Learning Sciences.

Ito, M., Antin, J., Finn, M., Law, A., Manion, A., Mitnick, S., ... \& Horst, H. A. (2009). Hanging out, messing around, and geeking out: Kids living and learning with new media. Cambridge, MA: MIT Press.

Jenkins, H., Purushotma, R., Weigel, M., Clinton, K., \& Robison, A. J. (2009). Confronting the challenges of participatory culture: Media education for the $21^{\text {st }}$ century. Cambridge, MA: MIT Press.

Kahne, J., Middaugh, E., Lee, N. J., \& Feezell, J. T. (2012). Youth online activity and expos ure to diverse perspectives. New Media \& Society, 14(3), 492-512. http://dx.doi.org/10.1177/1461444811420271 
(2016). Revea ling opportunities for $21^{\text {st }}$ century learning: An approach to interpreting user trace log data. Journal of Learning Ana lytics, 3 (2), 37-87. http:// dx.doi.org/10.18608/jla.2016.32.4

Koper, R., \& Tattersall, C. (2004). New directions for lifelong learning using network technologies. British Journal of Educational Technology, 35(6), 689-700. http://dx.doi.org/10.1111/j.14678535.2004.00427.x

Lave, J., \& Wenger, E. (1991). Situated learning: Legitimate peripheral participation. Cambridge, UK: Cambridge University Press.

Lenhart, A. (2015). Teen, social media and technology overview report 2015. Washington, DC: Pew Research Center. Retrieved from http://www.pewinternet.org/files/2015/04/PI_TeensandTech_Update2015_0409151.pdf

Levy, F., \& Murnane, R. J. (2004). The new division of labor: How computers are creating the next job market. Princeton, NJ: Princeton University Press.

Madison-Boyd, S., \& Steele, J. (2015, April). Designing a pathway to support teen engagement in writing. Paper presented at the American Educational Research Association Conference during the session on New Tools, New Voices: Innovations in Understanding and Analyzing Life-Wide Ecologies for Youth Interest-Driven Learning, Chicago, IL, USA.

Martin, C. K., \& Pinkard, N. (forthcoming). Digital Youth Network. In K. Peppler (Ed.), The SAGE encyclopaedia of out-of-schoollearning. New York: SAGE.

McGloughlin, C., \& Lee, M. (2010). Personalised and self-regulated learning in the Web 2.0 era: International exemplars of innovative pedagogy using social software. Australian Journal of Educational Technology, 26(1), 28-43. Retrieved from http://ajet.org.au/index.php/AJET/article/view/1100

Means, B., Bakia, M., \& Murphy, R. (2014). Learning online: What research tells us about whether, when and how. New York: Routledge.

Nacu, D., Martin, C. K., Schutzenhofer, M., \& Pinkard, N. (2016). Beyond traditional metrics: Using automated log coding to understand $21^{\text {st }}$ century learning online. Proceedings of the $3^{\text {rd }} A C M$ Conference on Learning@Scale (L@S 2016), 197-200. http://dx.doi.org/10.1145/2876034.2893413

Nacu, D., Martin, C. K., Pinkard, N., \& Gray, T. (2014): Analyzing educators' online interactions: A framework of online learning support roles. Learning, Media and Technology, 41(2), 283-305. http://dx.doi.org/10.1080/17439884.2015.975722

National Governors Association Center for Best Practices \& Council of Chief State School Officers. (2010). Common core state standards. Washington, DC: The National Academies Press.

NGSS Lead States. (2013). Next generation science standards: For states, by states. Washington, DC: The National Academies Press.

Partnership for $21^{\text {st }}$ Century Skills. (2011). $21^{\text {st }}$ century learning environments (White paper). Tucson, AZ: Partnership for $21^{\text {st }}$ Century Skills. Retrieved from http://www.p21.org/storage/documents/p21stateimp learning environments.pdf

Pellegrino, J. W., \& Hilton, M. L. (Eds.). (2012). Education for life and work: Developing transferable knowledge and skills in the $21^{\text {st }}$ century. Washington DC: National Academies Press. 
(2016). Revealing opportunities for $21^{\text {st }}$ century learning: An approach to interpreting user trace log data. Journal of Learning Ana lytics, 3 (2), 37-87. http:// dx.doi.org/10.18608/jla.2016.32.4

Peppler, K. (2013). New opportunities for interest-driven arts learning in a digital age (Report). New York: Wallace Foundation. Retrieved from http://www.wallacefoundation.org/knowledgecenter/Documents/New-Opportunities-for-Interest-Driven-Arts-Learning-in-a-Digital-Age.pdf

Reich, J., Murnane, R., \& Willett, J. (2012). The state of wiki usage in US K-12 schools leveraging web 2.0 data warehouses to assess quality and equity in online learning environments. Educational Researcher, 41(1), 7-15. http://dx.doi.org/10.3102/0013189X11427083

Robbie, D., \& Zeeng, L. (2008). Engaging student social networks to motivate learning: Capturing, analysing and critiquing the visual image. The International Journal of Learning , 15(3), 153-160.

Salaway, G., Caruso, J. B., \& Nelson, M. R. (2008). The ECAR study of undergraduate students and information technology, 2008. Boulder, CO: Educause Center for Applied Research.

Selwyn, N. (2009). Faceworking: Exploring students' education-related use of Facebook. Learning, Media and Technology, 34, 157-174. http://dx.doi.org/10.1080/17439880902923622

Silvia, P. J., Winterstein, B., Willse, J., Barona, C., Cram, J., Hess, K., Martinez, J., \& Richard, C. (2008). Assessing creativity with divergent thinking tasks: Exploring the reliability and validity of new subjective scoring methods. Psychology of Aesthetics, Creativity, and the Arts, 2(2), 68-85.

Shute, V. J., \& Ventura, M. (2013). Stealth assessment: Measuring and supporting learning in video games. Cambridge, MA: MIT Press.

Siemens, G., \& Long, P. (2011). Penetrating the fog: Analytics in learning and education. Educause Review, 46(5), 30. Retrieved from https://net.educause.edu/ir/library/pdf/ERM1151.pdf

Siemens, G. (2012). Learning analytics: Envisioning a research discipline and a domain of practice. Proceedings of the $2^{\text {nd }}$ International Conference on Learning Analytics and Knowledge (LAK '12), 4-8. http://dx.doi.org/10.1145/2330601.2330605

Ullman, C., \& Rabinowitz, M. (2004, October 1). Course management systems and the reinvention of instruction. THE Journal. Retrieved from https://thejournal.com/articles/2004/10/01/coursemanagement-systems-and-the-reinvention-of-instruction.aspx

US Department of Education, Office of Educational Technology. (2010). Transforming American education: Learning powered by technology (National Educational Technology Plan). Washington, DC: US Department of Education.

Vossoughi, S., \& Bevan, B. (2014). Making and tinkering: A review of the literature (Report for the National Research Council Committee on Out of School Time STEM). Washington, DC: National Research Council.

Walter, S. (2010). Raiding virtual middle earth: Collaborative practices in a community of gamers (Doctoral dissertation, Stanford University, USA). Retrieved from https://purl.stanford.edu/bx879yp6017

Watson, J., Murin, A., Vashaw, L., Gemin, B., \& Rapp, C. (2011). Keeping pace with K-12 online learning: An annual review of policy and practice. Durango, CO: Evergreen Education Group. Retrieved from http://kpK-12.com/cms/wp-content/uploads/KeepingPace2011.pdf

Wing, J. M. (2006). Computational thinking. Communications of the ACM, 49(3), 33-35. http://dx.doi.org/10.1145/1118178.1118215 
(2016). Revea ling opportunities for $21^{\text {st }}$ century learning: An approach to interpreting user trace log data. Journal of Learning Ana lytics, 3 (2), 37-87. http:// dx.doi.org/10.18608/jla.2016.32.4

Wing, J. M. (2011, March 6). Research notebook: Computational thinking - what and why? The Link: The Magazine of the Carnegie Melon University School of Computer Science, 6, 20-23. Retrieved from https://www.cs.cmu.edu/link/research-notebook-computational-thinking-what-and-why 